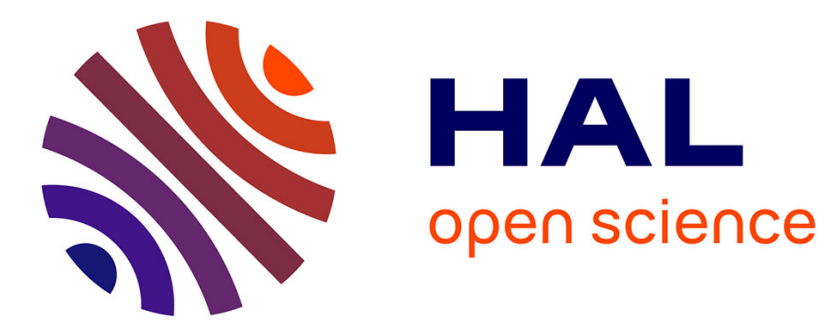

\title{
Social Games and Genic Selection Drive Mammalian Mating System Evolution and Speciation
}

Barry Sinervo, Alexis Chaine, Donald Miles

\section{To cite this version:}

Barry Sinervo, Alexis Chaine, Donald Miles. Social Games and Genic Selection Drive Mammalian Mating System Evolution and Speciation. American Naturalist, 2020, 195 (2), pp.247-274. 10.1086/706810 . hal-03013292

\section{HAL Id: hal-03013292 \\ https://hal.science/hal-03013292}

Submitted on 26 Nov 2020

HAL is a multi-disciplinary open access archive for the deposit and dissemination of scientific research documents, whether they are published or not. The documents may come from teaching and research institutions in France or abroad, or from public or private research centers.
L'archive ouverte pluridisciplinaire HAL, est destinée au dépôt et à la diffusion de documents scientifiques de niveau recherche, publiés ou non, émanant des établissements d'enseignement et de recherche français ou étrangers, des laboratoires publics ou privés. 


\title{
Social Games and Genic Selection Drive Mammalian Mating System Evolution and Speciation
}

\author{
Barry Sinervo, ${ }^{1,2}$ Alexis S. Chaine, ${ }^{2,3 *}$ and Donald B. Miles ${ }^{2,4}$ \\ 1. Department of Ecology and Evolutionary Biology, University of California, Santa Cruz, California 95064; 2. Station d'Ecologie \\ Théorique et Expérimentale du CNRS (Unité Mixte de Recherche 5321), 2 Route du CNRS, 09200 Moulis, France; 3. Institute for \\ Advanced Studies in Toulouse, Toulouse School of Economics, 21 Allée de Brienne, 31015 Toulouse, France; 4. Department of Biological \\ Sciences, Ohio University, Athens, Ohio 45701
}

Submitted December 12, 2018; Accepted July 29, 2019; Electronically published December 18, 2019

Online enhancements: supplemental material.

ABSTRACT: Mating system theory based on economics of resource defense has been applied to describe social system diversity across taxa. Such models are generally successful but fail to account for stable mating systems across different environments or shifts in mating system without a change in ecological conditions. We propose an alternative approach to resource defense theory based on frequencydependent competition among genetically determined alternative behavioral strategies characterizing many social systems (polygyny, monogamy, sneak). We modeled payoffs for competition, neighborhood choice, and paternal care to determine evolutionary transitions among mating systems. Our model predicts four stable outcomes driven by the balance between cooperative and agonistic behaviors: promiscuity (two or three strategies), polygyny, and monogamy. Phylogenetic analysis of 288 rodent species supports assumptions of our model and is consistent with patterns of evolutionarily stable states and mating system transitions. Support for model assumptions include that monogamy and polygyny evolve from promiscuity and that paternal care and monogamy are coadapted in rodents. As predicted by our model, monogamy and polygyny occur in sister taxa among rodents more often than by chance. Transitions to monogamy also favor higher speciation rates in subsequent lineages, relative to polygynous sister lineages. Taken together, our results suggest that genetically based neighborhood choice behavior and paternal care can drive transitions in mating system evolution. While our genic mating system theory could complement resource-based theory, it can explain mating system transitions regardless of resource distribution and provides alternative explanations, such as evolutionary inertia, when resource ecology and mating systems do not match.

Keywords: ESS, social games, mammals, mating systems, genic behavior. * Corresponding author; email: alexis.chaine@cnrs.fr.
ORCIDs: Sinervo, https://orcid.org/0000-0002-9241-1821; Chaine, https://
orcid.org/0000-0003-3346-551X; Miles, https://orcid.org/0000-0001-5768-179X.

Am. Nat. 2020. Vol. 195, pp. 000-000. (C) 2019 by The University of Chicago. 0003-0147/2020/19502-58938\$15.00. All rights reserved.

DOI: $10.1086 / 706810$

\section{Introduction}

Mating systems play a critical role in genetic, demographic, and social dynamics of populations. Prevailing models explaining mating system diversity emphasize links between resource and mate monopolization. If resources are defensible, polygynous males on high-quality territories will have access to more females than monogamous males on lowquality territories (Verner and Willson 1966; Orians 1969), and temporal variation in mate availability or sex ratio further accentuates this dichotomy between polygyny and monogamy (Emlen and Oring 1977; Houston et al. 2013; Gomes et al. 2018). However, paternal care can shift the advantage to a monogamous system (Maynard Smith 1977; Wakano and Ihara 2005; Jungwirth and Johnstone 2018). Indeed, the diversity of factors thought to influence variation in mating systems has led to calls for more integrative models to better predict mating system evolution, including the above considerations (Komers and Brotherton 1997; Houston et al. 2013; Klug 2018; Kvarnemo 2018) as well as social interactions (Alonzo 2010; Dillard and Westneat 2016). However, most past models, with some exceptions, favored extrinsic factors (e.g., resources, operational sex ratio, mate defensibility) in explaining the evolution of mating systems (e.g., Sandell and Liberg 1992; Ptak and Lachmann 2003; Gomes et al. 2018; reviewed in Vehrencamp and Bradbury 1984; Davies 1991; Shuster and Wade 2003). Few models include social competition and intrinsic genetic factors in driving mating system evolution or the likelihood of transitions between mating system states (Wakano and Ihara 2005; Alonzo 2007; Jungwirth and Johnstone 2018; see also Alonzo 2010; Dillard and Westneat 2016). Likewise, most empirical approaches to understanding such transitions have focused on extrinsic factors (Komers and Brotherton 1997; Lukas and Clutton-Brock 2013; Kvarnemo 2018). This is problematic because while the environment and the distribution of resources may change and shift the economic 
advantages of a particular mating system, an existing mating system may remain static, given evolutionary inertia (i.e., lack of phenotypic change across species due to intrinsic factors) and the existence of genetically based mating system strategies. Likewise, intrinsic genetic factors could shift a mating system with no ostensible change in resource distribution in the environment (see also Alonzo 2010; Dillard and Westneat 2016). The limited theoretical attention to intrinsic factors means that we have an incomplete understanding of how genetically based alternative mating strategies affect the evolution of mating systems relative to extrinsic mechanisms. We propose that by influencing social interactions, genetic mechanisms underlying mating system strategies complement resource-based ecological approaches and could also shape mating system evolution independent of the defensibility of resources.

Frequency-dependent competition among genetically determined behavioral types could provide a general explanation for mating system evolution among species. Indeed, such competition drives mating systems within species (e.g., lizards [Sinervo 2001], birds [Küpper et al. 2016; Lamichhaney et al. 2016], isopods [Shuster and Sassaman 1996], and damselflies [Cordero et al. 1998; Svensson et al. 2005]) and can generate divergence between populations (Corl et al. 2010). Furthermore, genetic models of frequencydependent competition may apply to diverse taxa. Recent molecular studies have revealed a genetic basis of male behavior in a number of species (Bester-Meredith et al. 1999; Young 1999; Lim and Young 2004; Young and Wang 2004; Ophir et al. 2008; Walum et al. 2008), including alternative male strategies and their underlying behaviors (Bishop et al. 2004; Knafo et al. 2008; Oliveira et al. 2008; Küpper et al. 2016; Lamichhaney et al. 2016). Here, we modeled such genetic strategies to test whether purely intrinsic factors associated with mating systems (i.e., genetically based fixed behaviors) predict evolutionary transitions among mating systems while ignoring the effects of resource availability and defensibility.

Game theoretic approaches have been used to model the evolution of mating systems since Maynard Smith (1977). His model explored the evolution of parental care and had implications for mating systems, since a defecting parent (i.e., one that provides no care) was assumed to seek additional mating opportunities. Indeed, this seminal article cemented the idea that monogamy and biparental care were linked (Houston et al. 2013; but see Komers and Brotherton 1997). The majority of such models focused on the conditions favoring monogamy or polygyny (e.g., Ranta and Kaitala 1999; Ptak and Lachmann 2003) or when multiple mating strategies coexist (e.g., Sinervo and Lively 1996). No doubt inspired by Emlen and Oring's (1977) verbal model, these game theoretic models investigated the influence of diverse factors on mating system evolution, such as the im- portance of parental care (Wakano and Ihara 2005; Jungwirth and Johnstone 2018), habitat quality (Ranta and Kaitala 1999), space use and the defensibility of resources (Sandell and Liberg 1992), and sex ratio (Kokko and Jennions 2008; Gomes et al. 2018). These models focused on the influence of extrinsic factors on mating system evolution. In contrast to these phenotypic models, a handful of studies examined how genetic systems might influence mating system evolution; these models yield surprising results (Ptak and Lachmann 2003; Sinervo et al. 2007; Moulherat et al. 2017). For example, Ptak and Lachmann (2003) showed that specific attention to allelic inheritance leads to a much broader state space where polygyny is stable based on a polygyny threshold scenario (i.e., resource defense polygyny). Likewise, Moulherat et al. (2017) showed that differences in gene expression (dominance vs. plasticity) alters the likelihood that a set of alternative male strategies is maintained within a population. Moreover, recent game theoretic models have suggested that social interactions can have important effects on model outcomes (Alonzo 2010; Dillard and Westneat 2016). For example, malefemale conflict (Alonzo 2007), male-male cooperative interactions (Sinervo et al. 2007), and female-female interactions (Jungwirth and Johnstone 2018) can all alter the conditions favoring the expression of different mating patterns. Taken together, inclusion of explicit inheritance rules and social behaviors driven by these genes can generate shifts in the patterns of mating system due to factors other than classical extrinsic drivers, such as resource distribution and operational sex ratio. Our goal here is to build on these past efforts to examine the evolution of mating systems due solely to the impact of genes on specific behaviors controlling social interactions. We focus on intrinsic factors and ignore resource distribution, sex ratio, and other extrinsic factors. Specifically, we add two new elements to past models. First, we model three alternative strategies as in past studies on the maintenance of alternative mating strategies (e.g., Sinervo et al. 2007; Moulherat et al. 2017), but with a focus on mating system state when alternative strategies are not maintained as well as cases when multiple strategies are maintained. Second, we model two social behaviors (neighborhood choice and paternal care) driven by genic recognition of others, as suggested in recent empirical work (Bester-Meredith et al. 1999; Mateo 2004; Sinervo et al. 2006; Holmes and Mateo 2007; Widdig 2007; Ophir et al. 2008).

We extend previous game theoretic models based on competition among three fixed genetic strategies (Sinervo et al. 2007; Friedman and Sinervo 2016) by including paternal care and social neighborhood choice to explore mating system evolution. Variation in the level of aggression and cooperation or care among genotypes should influence both the monopolization of space and thus mates as well 
as the degree of parental care provided by each strategy (Vehrencamp and Bradbury 1984; Davies 1991; Sinervo and Lively 1996; Shuster and Wade 2003; Schradin and Pillay 2005a). The strategies in our model can be described as (1) investment in aggression and therefore maintenance of a large territory overlapping with multiple females but without paternal care (polygyny); (2) lower aggression and smaller territory size but cooperation at territory boundaries (i.e., dear enemy effect [Temeles 1994]) coupled with investment in paternal care (monogamy); and (3) a nonterritorial strategy with no paternal care, which is often referred to as a sneaker strategy in otherwise territorial systems (sneak). Here, sneaker males employ deception to attain copulations through mimicking female behavior and avoiding male territorial interactions (Sinervo and Lively 1996; Alonzo et al. 2000; Jukema and Piersma 2006). We vary the fitness benefits of male care and neighborhood choice in our model to explore patterns of evolutionary transitions among mating system states. Our approach integrates the genetic contribution to competition within and among social strategies to show that specific behaviors facilitate evolutionary transitions in mating system regardless of resource distribution.

We test for qualitative consistency of assumptions and predictions of our model through phylogenetic comparative analyses using data on rodent mating systems and a well-supported phylogeny to identify social strategies associated with mating system transitions. The phylogenetic comparative analysis confirms key assumptions and predictions of our genetic model. While resourcebased and genetic explanations are likely complementary and could interact in interesting ways, our effort here demonstrates the important role that genetic strategies can play in mating system evolution irrespective of resource distribution considerations.

\section{Genetic Mating System Model}

We modeled frequency-dependent social competition among three genetically determined strategies using a game theoretic approach (Maynard Smith 1982). We assumed that fitness is determined by additive effects of alleles at a single locus in a diploid sexual organism (table S1; tables S1-S7 are available online; Alonzo and Sinervo 2001; Sinervo et al. 2007; Friedman and Sinervo 2016; Barreto et al. 2017; Moulherat et al. 2017). The single gene we model has effects on a number of behaviors and is similar to empirical findings in systems with a supergene (e.g., ruffs [Küpper et al. 2016; Lamichhaney et al. 2016]), pleiotropic effects on multiple behaviors (e.g., slime molds [Queller et al. 2003; Foster et al. 2004]), or both (e.g., lizards [Sinervo et al. 2006]). We include three alleles that correspond to common alternative mating strategies (polygyny, monog- amy, sneak) and have pleiotropic effects on behaviors (competition, settlement, care, and recognition). Allelic effects are represented by three genotypic payoff matrices described below (table S1) that determine offspring frequencies at recruitment for each diploid genotype (table S2). We explore how changing values of neighborhood choice (random settlement to four times higher probability of settlement by neighbors with specific strategy combinations) and paternal care (no care to threefold higher recruitment advantage of offspring) affect the evolutionarily stable strategy (ESS) mating system (Maynard Smith 1982) and transitions among mating systems.

Following population genetic theory (Wright 1968; Maynard Smith 1982; Sinervo and Lively 1996; Sinervo et al. 2007; Friedman and Sinervo 2016), we calculated the relative change in frequency of each of the six genotypes in adult cohorts described by the genotype vector $g$ (with elements $g_{i}$ and diploid subscripts $i=\boldsymbol{\rho} \boldsymbol{\rho}, \boldsymbol{\rho} \kappa, \boldsymbol{\rho} \boldsymbol{\sigma}$, $\boldsymbol{\kappa} \boldsymbol{\kappa}, \boldsymbol{\kappa} \boldsymbol{\sigma}, \boldsymbol{\sigma} \boldsymbol{\sigma}$, where alleles $\boldsymbol{\rho}=$ polygyny, $\boldsymbol{\kappa}=$ monogamy, and $\sigma=$ sneak):

$$
g(t+1)=s \times g(t)+(1-s) \times g^{\prime},
$$

which includes adults at time $t$ surviving $(s)$ to the next year $(t+1)$ and recruitment of each genotype by juveniles $\left(g^{\prime}\right)$, as described below (eq. [3]), who replace adults that do not survive $(1-s)$. Variation in adult survival $(s)$ had the sole effect of lengthening the periodicity of stable cycles when all three strategies were preserved, but no effect on the ESS.

We calculated genotype frequencies of juveniles by modifying the diploid genetic model proposed by Friedman and Sinervo (2016, eq. [5.11] in sec. 5.3) and Friedman et al. (2017, eq. 14 in supplemental material on inheritance from two parents). Note that here we modify variable names of the original to reflect the characters and behaviors in our extended model. In that model, frequencies of juveniles at recruitment are given by the vector $g^{\prime}$ (called $s$ in the original, with elements $g_{i}$ and diploid subscripts $i=\boldsymbol{\rho} \rho, \boldsymbol{\rho} \kappa, \boldsymbol{\rho \sigma}$, $\boldsymbol{\kappa} \boldsymbol{\kappa}, \boldsymbol{\kappa} \boldsymbol{\sigma}, \boldsymbol{\sigma} \boldsymbol{\sigma}$, where haploid alleles $\boldsymbol{\rho}=$ polygyny, $\boldsymbol{\kappa}=$ monogamy, and $\sigma=$ sneak), which is calculated by

$$
g^{\prime}=c g^{\mathrm{F}} \mathbf{F} \circ \mathbf{A} \circ\left[H^{1}, \ldots, H^{6}\right] \circ \mathbf{B} \circ \mathbf{M} g^{\mathrm{M}},
$$

where $g$ is a vector of genotype frequencies (variable $s$ in the original) and the superscripts refer to the diploid genotype of adult males $\left(g^{\mathrm{M}}\right)$, females $\left(g^{\mathrm{F}}\right)$, and juveniles $\left(g^{\prime}\right)$; $\left[H^{1}, \ldots, H^{6}\right]$ describes allele inheritance rules (see below), and matrices $\mathbf{F}, \mathbf{M}, \mathbf{A}$, and $\mathbf{B}$ reflect the outcome of survival of females $(\mathrm{F})$ and males $(\mathrm{M})$ and mate preferences of females (A) and males (B). We modified that model by first replacing survival matrices (F, M) — which we account for in equation (1) but which does not include genotypespecific survival rates - with fitness payoff matrices $(\Phi)$. 
Second, we replaced mate choice behavioral matrices (A, B) with ones describing discrimination (D) and parental care behavior $(\mathbf{P})$ in males. Values for these new matrices in our model are given in table S1, and we describe the behavior associated with each in separate sections below. Our modified model becomes

$$
g^{\prime}=c g^{\mathrm{F}} \Phi^{\mathrm{F}} \circ\left[H^{1}, \ldots, H^{6}\right] \circ \mathbf{P} \circ \mathbf{D} \circ \Phi^{\mathrm{M}} g^{\mathrm{M}} .
$$

This matrix formulation presents the order of events of reproduction, with female parental genotypes to the left $\left(g^{\mathrm{F}}\right)$, males to the right $\left(g^{\mathrm{M}}\right)$, and Mendelian ratios forming progeny in the middle $\left[H^{1}, \ldots, H^{6}\right]$ that are modified by selection on females $\left(\boldsymbol{\Phi}^{\mathrm{F}}\right)$ and males $\left(\mathbf{D} \circ \mathbf{P} \circ \Phi^{\mathrm{M}}\right)$. Genotype frequencies in the next generation $\left(g^{\prime}\right)$ are a product of parental genotypes (female $g^{\mathrm{F}}$, male $g^{\mathrm{M}}$ ) combined to produce Mendelian ratios with a hex matrix consisting of $6 \times 6$ elements (table S2). Each of the $6 \times 6$ elements of the hex matrix contain six-element vectors, $\left[H^{1}, \ldots, H^{6}\right]$, that are Markov transition probabilities (i.e., Mendelian ratios) for progeny genotypes from random mating of a female genotype ( $i$; rows) and a male genotype ( $j$; columns). Given an equal sex ratio and no sex-specific selection, the frequencies of male and female genotypes of juveniles are symmetrical. Mendelian ratios are then modified by selection in matrices that describe competition ( $\Phi$ ) and male behaviors (D and $\mathbf{P})$.

Payoffs from frequency-dependent competition among adult genotypes are described by the $6 \times 6$ matrix $\Phi$ as the outcome of competition between each strategy interacting with each of the other strategies as a result of social competition over mates $\left(\boldsymbol{\Phi}\right.$ is a $6 \times 6$ payoff matrix $=\left(\left(\varphi_{i, j}\right)\right)$; Sinervo and Lively 1996; Friedman et al. 2017). Payoffs are modified by matrices $\mathbf{D}$ and $\mathbf{P}$, which describe nonrandom association behaviors between individuals (see below; table S1). Matrix D describes choice of social neighborhood based on the genotypes that favor a focal individual's fitness ( $\mathbf{D}$ is discrimination or targeting; see also Sinervo et al. 2007; Friedman and Sinervo 2016). Matrix P describes the association of male care behaviors from paternal care ( $\mathbf{P}$ is paternal behavior). This matrix formulation is described in detail by Friedman and Sinervo (2016), and we use the Hadamard product notation (denoted by $\circ$ ), which describes element-by-element multiplication between the behavioral matrices, $\mathbf{P}$ and $\mathbf{D}$ (for a full description of this approach, see chap. 5 in Friedman and Sinervo 2016; for a model with additive genetic effects, see supplementary information in Friedman et al. 2017), whereas the products between other matrices $(\boldsymbol{\Phi})$ and vectors $(g)$ are given by normal matrix multiplication among vectors or matrices. The scalar $c$ is the normalization product required to obtain $\Sigma g_{i}^{\prime}=1$, following selection acting on the parental generation.
The competition matrices $(\boldsymbol{\Phi})$ provide estimates of fitness due to social competition within each sex. In the current model, we ignore frequency-dependent competition among female strategies $\left(\Phi^{\mathrm{F}}\right)$ by setting all matrix elements to 1 . The male competition payoff matrix ( $\Phi^{\mathrm{M}}$; table S1A) describes the success of each male strategy in competition to acquire territory and mating opportunities either directly with females whose territories overlap or extrapair from females on neighboring territories (especially sneak). Competition occurs between each genotype pair in proportion to the frequency of those genotypes in the population (i.e., randomized encounters between males, modified by $\mathbf{D}$ and $\mathbf{P}$ below). The competition matrix $\left(\boldsymbol{\Phi}^{\mathrm{M}}\right)$ then describes the biases in the representation of alleles in the next generation (i.e., biases in fitness, either direct or extrapair) dependent on which strategies compete. We assume fitness intransitivity for competition ( $\Phi^{M}$ matrix) among the three alternative alleles (polygyny $>$ monogamy $>$ sneak $>$ polygyny; table S1A), which holds when expanded to all genotype pairs (table S1D). Such intransitivity is critical for a stable trimorphism (Bomze 1983; Sinervo and Lively 1996; Sinervo et al. 2007; Friedman and Sinervo 2016; Moulherat et al. 2017) and has been described in a number of species with very broad taxonomic coverage ranging from bacteria to plants to vertebrates (Sinervo and Calsbeek 2006; chap. 7 in Friedman and Sinervo 2016). In such systems, polygynous males are aggressive and outcompete monogamous males, but defense of larger harems by polygynous males makes them more susceptible to a sneak strategy. In contrast, monogamous males defend their single partner closely and therefore are not easily usurped by sneak. Furthermore, both polygyny and sneak adults have limited fitness when common as a result of density-dependent competition (i.e., competing with males of the same strategy; payoff $_{\rho, \rho}=c<1$, payoff ${ }_{\sigma, \sigma}=k<1$; table S1A), whereas monogamous males do not (payoff ${ }_{k, k}=1$ ) since they maintain stable territorial boundaries with neighbors of the same genotype (dear enemy effect; Temeles 1994).

The neighborhood choice matrix (D; table S1B) describes the ability of juvenile males to recognize and settle in specific neighborhoods of adult male genotypes that will maximize their fitness. Discrimination behavior $(d)$, which we have previously argued is a consequence of intransitive strategies (Sinervo et al. 2007; chap. 7 in Friedman and Sinervo 2016), allows individuals to seek out neighborhoods where they are competitively superior (Frean and Abraham 2001; Sinervo et al. 2007; table S1B). The level of discrimination, $\mathbf{D}_{i^{\prime}, i}$, produces the additive allelic fitness effect of this behavior $\left(\mathbf{D}_{\kappa, \sigma}\right.$, $\mathbf{D}_{\rho, \kappa}$, and $\mathbf{D}_{\sigma, \rho} ; d>1$, otherwise $d=1$; table S1B, S1D). Filiative $(f)$ behavior is a parameter in the neighborhood choice payoff matrix that enhances self-genotype clustering among monogamous genotypes $\left(\mathbf{D}_{\kappa, \kappa} ; f>1\right)$ to benefit from nonaggressive genetically similar neighbors (Sinervo 
et al. 2006, 2007). The benefit of filiative behavior is calculated by the overlap in monogamy alleles between neighbors as an additive effect of alleles (table S1D). Both neighborhood choice and care behavior could occur either through direct genic recognition (as assumed in this model) or through other mechanisms, such as kin philopatry, strategy recognition, biased dispersal, or specific social habitat choice.

The paternal care payoff matrix (P; table S1C) describes effects of care by adult males on offspring recruitment (table $\mathrm{S} 1 \mathrm{C}-\mathrm{S} 1 \mathrm{E})$. We assume that paternal care is restricted to individuals with monogamy alleles who invest in offspring quality $\left(\mathbf{P}_{\kappa, \kappa} ; p>1\right.$, otherwise $p=1$; table S1C) rather than additional mates through social competition with other males (e.g., the competition payoff matrix, $\boldsymbol{\Phi}^{\mathrm{M}}$ ). This assumption is consistent with recent analyses in rodents showing that the same genes have effects on monogamy, affiliative behavior, and parental care (Bester-Meredith et al. 1999; Ferguson et al. 2001; Lim and Young 2004; Young and Wang 2004; Ophir et al. 2008; Schradin 2008; Okhovat et al. 2015). Care is given in direct proportion to the genetic similarity between sire and offspring as an additive allelic effect (probability of sharing $\boldsymbol{\kappa}$ alleles; table S1D, $\mathrm{S} 1 \mathrm{E})$ and thus depends on both paternal (M) and maternal (F) genotypes. We have modeled male care through genic recognition rather than care allocated equally to all young by monogamous males for two reasons. First, paternal care via allelic recognition of sire-offspring pairs is internally consistent with neighborhood choice behavior (matrix D), which also requires some sort of genic recognition. Second, such forms of recognition tied to social relationships, including paternal care, are observed in nature (Wang et al. 1994, 1998; Bester-Meredith et al. 1999; Marler et al. 2003; Mateo 2003; Neff 2003; Holmes and Mateo 2007; Widdig 2007; Nam et al. 2010). Care provided equally to all offspring regardless of allelic overlap would likely weaken selection and could form an interesting extension to our current model. Male care need not be elaborate but supplements maternal care through behaviors such as nest defense or thermoregulation to enhance progeny survival (see also Lukas and Clutton-Brock 2013). In contrast, polygyny and sneak genotypes provide no care and abandon progeny to seek out other mates.

\section{Simulation Results}

We used equations (1) and (3) to calculate gene frequencies across time and examine ESS mating systems for a given set of parameter values by searching for the central tendency after 1,000 generations (Sinervo et al. 2007; ESS usually fixed within 200 generations). To explore how behavior affects transitions between ESS mating systems, we varied parameters with particular emphasis placed on explo- ration of discrimination $(1<d<5)$, filiative $(1<f<4)$, and paternal care behaviors $(1<p<4)$. The model assumed equal initial frequencies of all three alleles, but we also explored simulations with random start frequencies (1,000 starts for each parameter combination, fig. S1; figs. S1-S6 are available online).

Evolutionarily stable social systems are determined by conflict between competitive (discrimination) and cooperative behaviors (filiative, paternal; Hochberg et al. 2003), which clearly drive ESS outcomes of our model. Mating system simulations after 1,000 generations predicted one of four cases: (1) a noncycling stable equilibrium between polygyny and sneak alleles, (2) a stable interior attractor of all three alleles (length of cycles was verified for $>500$ generations; Sinervo et al. 2007), or (3) a pure ESS (single allele) of either polygyny (a) or monogamy (b; figs. 1, S2). The mixed ESS (sneak and monogamy) was never stable, and sneak alone was never an ESS.

Case 1. Stable coexistence between sneak and polygyny or a mixed ESS mating system, occurred for only a narrow parameter range when discrimination was absent $(d=1$; random settlement) and both filiative and paternal care were low $(f<1.3, p<1.8$; values represent recruitment advantages of young over baseline levels; see bottom left of fig. 1 , where $d=1$ ).

Case 2. All strategies are retained in a rock-paper-scissors (RPS) cycle, which is either a Nash equilibrium (Sinervo and Lively 1996) or a mixed ESS akin to a multiple paternity mating system in circumstances where territory boundaries of alternative strategies within sex overlap somewhat and between-sex territories are unrelated (Sinervo and Lively 1996). Friedman and Sinervo (2016) discuss differences in Lotka-Volterra dynamics of an RPS that is an ESS versus a Nash equilibrium, but both game states retain three strategies because of RPS intransitivity with a stable interior attractor (Bomze 1983). The length of RPS cycles varied as a function of model parameters (discussed below). Such systems generate promiscuity as a result of multiple paternity patterns, but empirical spacing patterns (e.g., high variance in space use among individuals) suggest that they may contain alternative mating strategies described in our model. We therefore use the common term "promiscuity" to describe this mating system outcome with the coexistence of three alternative male strategies. Stronger densitydependent competition within the two male strategies of polygyny and sneak (low $c, k$ ) generally increased the stability of RPS cycles and coexistence as in past models (Sinervo et al. 2007). Similarly, better discrimination behavior (higher $d$ ) enhanced coexistence and cycle stability (see also Sinervo et al. 2007). 

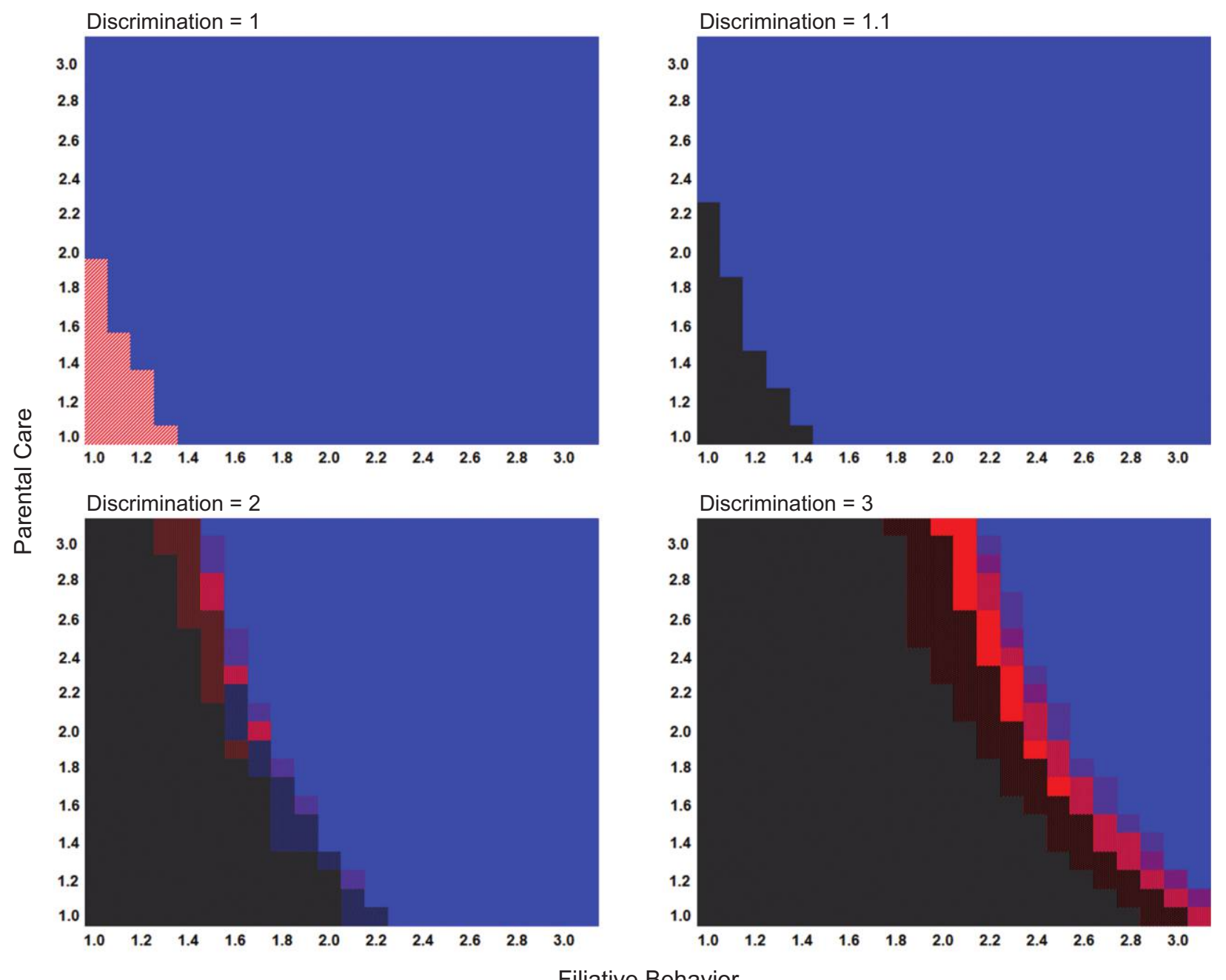

Figure 1: Shifts in evolutionarily stable strategy (ESS) mating system with increasing discrimination along a filiative and paternal care gradient. Mating system ESS as a function of filiative (self-attraction) and paternal care behaviors in monogamy for specific values of discrimination showing how polygyny only (red) resides in the parameter space between monogamy only (blue) and rock-paper-scissors promiscuity (black). Stippled areas for higher levels of discrimination represent domains where initial allele frequencies influence the ESS (in $>10 \%$ of cases), with the dominant color being most commonly fixed (see fig. S1, available online). Notice that hatched red-gray zones (bottom left) for $d=1$ reflect the only stable equilibrium between polygyny and sneak.

Case 3. Sneak is always lost, but either polygyny (case 3a) or monogamy (case $3 \mathrm{~b}$ ) is the pure ESS (fig. 1). As monogamy genotypes become prevalent (i.e., $p, f$ increase), fitness of sneak is depressed through more frequent encounters with this superior competitor.

The ESS in case 3 (polygyny vs. monogamy) depends on levels of paternal care and filiative behaviors (red vs. blue areas in figs. 1, S2). Counterintuitively, polygyny fixes when monogamy has moderate levels of filiative and paternal behaviors (high levels of one or moderate levels of both; figs. 1, S2). This is because as the fitness of monogamy increases, sneak is rapidly eliminated, thereby removing polygyny's dominant competitor. However, moderate monogamous behaviors are insufficient to outcompete polygyny, which is superior in male-male competition $\left(\Phi^{\mathrm{M}}\right)$. As combinations of paternal and filiative behaviors increase (above $\sim 1.5$-fold higher fitness), polygyny is outcompeted, leaving monogamy as a pure ESS (see also Ranta and Kaitala 1999). As discrimination behavior increases, the ESS domain for polygyny expands because its fitness is enhanced by settling near clusters of monogamous males (increasing $d$ across panels in fig. 1). Between the two pure ESS domains, a band of parameter values can fix for polygyny or monogamy or stay entrained in an RPS (promiscuity) depending on initial allele frequencies (figs. 1, S1). Thus, a mixed polygyny-monogamy state 
should be rare and exist as only an unstable or quasi-stable equilibrium, which rapidly bifurcates to monogamy or polygyny depending on initial allele frequencies (fig. 1 when $d>1$; fig. S1).

\section{Empirical Test of the Model}

We tested qualitative predictions about evolutionary transitions and ESS mating systems made by our model by comparing them with data (table S3) on the phylogenetic distribution of mating systems in rodents. We chose to test our model in rodents because considerable data on mating systems exist in the literature and because evidence for a genetic basis of the behaviors we model has been described (discussed in detail below). Extant rodent mating systems are often diagnosed by territorial spacing patterns among males and females or paternity, and categorization is congruent in taxa where both data are available (table S3; see methods for search strategy and categorization in the supplemental material). For taxa with sufficient data $(N=288)$, mating system was categorized as promiscuous (two to three strategies within a population; $N=161$ ), monogamous $(N=74)$, polygynous $(N=44)$, and mixed polygynymonogamy $(N=9)$.

We surveyed peer-reviewed articles, reviews, books, and unpublished theses with sufficient information to infer mating system states in the order Rodentia (table S3). We categorized mating systems using (in order of priority) (1) genetic paternity and (2) degree of overlap of home ranges within and between each sex. Because extrapair paternity occurs at a low level even in monogamous species, we designated some taxa as monogamous if home range and social patterns suggested monogamy, despite evidence of extrapair offspring ( $<20 \%$ extrapair young). Molecular and home range data generally suggested the same mating system when both were available for the same species. In general, our approach for assessing species mating system agreed with past reviews (e.g., Waterman 2007), but in a few instances, our method yielded a different mating system (see footnotes in table S3) or we did not deem the primary data sufficient to categorize mating system in a species included elsewhere (indeterminate in table S3; figs. 2, S3). Our criteria for categorizing a species as showing paternal care behavior required clear evidence of male behavior (care/no care) in natural or seminatural systems (table S3; see also Lukas and Clutton-Brock 2013).

We used the well-supported, time-calibrated phylogeny of rodents from Fabre et al. (2012) for our analyses on evolutionary transitions and speciation rates in rodent mating systems. We also included paternal care in our analyses to ascertain its association with mating system, which was an assumption of our model. Analyses were conducted in the R 3.5 environment ( $\mathrm{R}$ Development Core Team
2018). We first tested whether among-species variation in mating system exhibited phylogenetic signal using the fitDiscrete function in the GEIGER package (Harmon et al. 2008). We applied the lamba transformation to obtain an estimate of phylogenetic signal. Next, we examined evolutionary transitions in mating system across the phylogeny by reconstructing ancestral character states using maximum likelihood. We used the ace function in the APE package (ver. 5.1; Paradis et al. 2004) and an asymmetric Mk model of evolution to reconstruct ancestral states. Within this model, we compared different models of evolutionary change, including equal rates, symmetric rates, and all rates different using the fitDiscrete function in the GEIGER package (Harmon et al. 2008). The all rates different model had a significantly lower log likelihood and Akaike information criterion (AIC) score (table S4). We determined unambiguous transitions to monogamy using the criterion of Mooers and Schluter (1999), where a difference of 2 between the log likelihood of any of the states is considered a clear transition. We used this maximum likelihood reconstruction to compare dates of origin of each mating system (monogamous, polygynous, and promiscuous) with a nested ANOVA since our model predicted that polygyny should arise as a consequence of (i.e., after) increased monogamous behaviors (increases in polygyny [red areas] in fig. 1 when $d \geq 2$ and fig. S1 when care behavior $p$ increases). We estimated the proportion of transitions and time spent in different mating system states with a Bayesian stochastic character mapping analysis (Bollback 2006) to account for uncertainty in ancestral mating system states. The stochastic character mapping involved using the make.simmap function in the phytools package (Revell 2012). This function first estimates the conditional likelihood of each character state at all nodes of the tree. Next, it samples the posterior distribution of the transition rate matrix Q 1,000 times (100,000 generations sampled every 100 generations) using a Bayesian Markov chain Monte Carlo (MCMC). We estimated pi, the prior distribution of the root, from the results of the MCMC simulations. The output of stochastic character mapping includes the transition rate matrix $\mathbf{Q}$, the proportion of time spent in each character state, and the final transition probabilities.

Sparse or unbalanced data sampling across a phylogeny could bias results of ancestral reconstruction of mating systems states (Salisbury and Kim 2001), which could be a concern given that we have sampled 276 of 2,277 species in Rodentia (ignoring subspecies). Our sample includes species from all six major clades identified by Fabre et al. (2012): Sciuroidea, Castorimorph, Ctenohystrica, Anomaluromorpha, Myomorpha, and Muroidea (table S5). In addition, we have species from $74 \%$ (31 of 42) of the recognized families/subfamilies and $26 \%$ of the genera (124 of $474)$ in the order Rodentia. Mating system was also not 

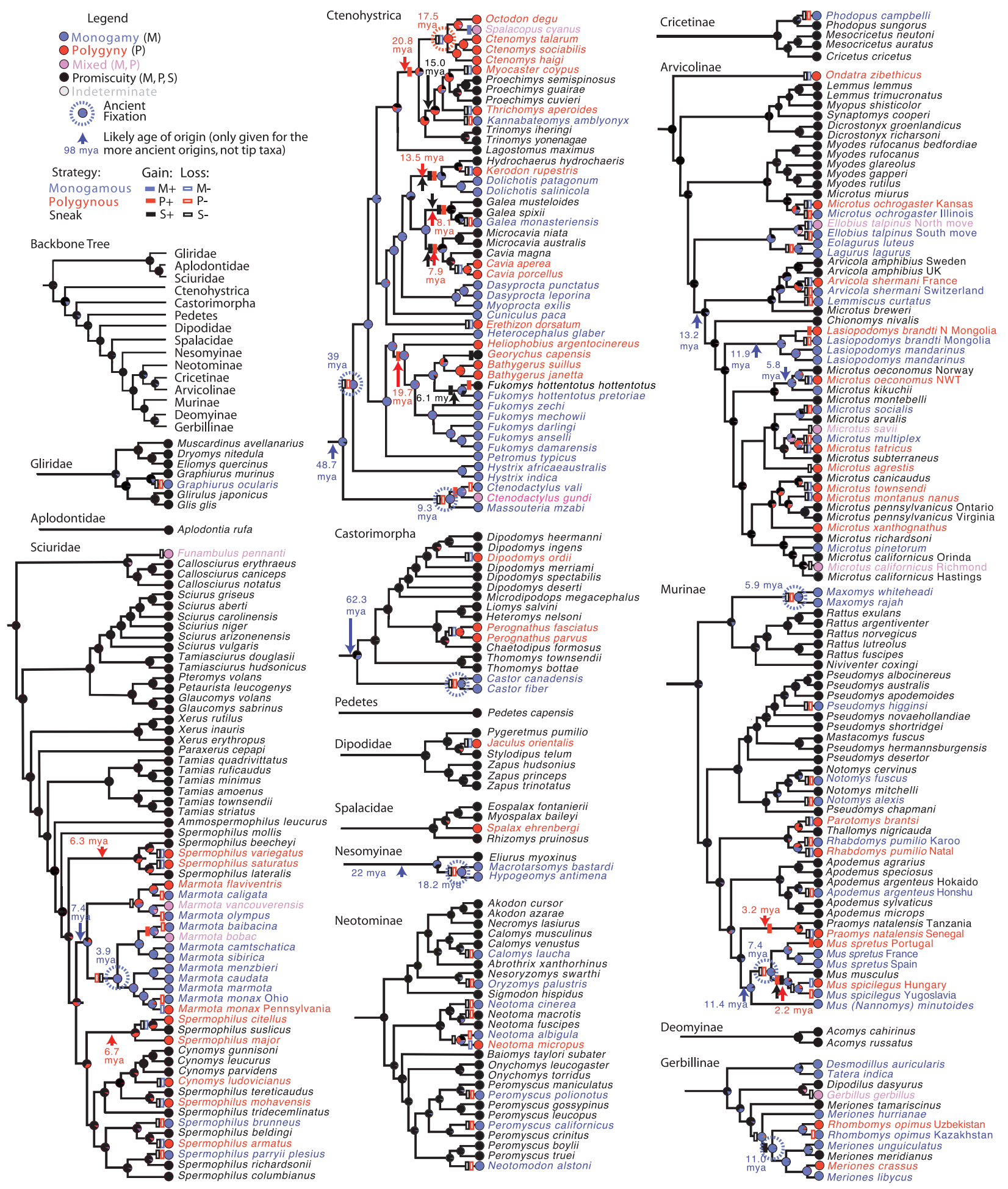

Figure 2: Ancestor reconstruction and distribution of mating systems mapped onto the rodent phylogeny using maximum likelihood. Mating systems are classified as monogamous (blue), polygynous (red), mixed monogamy-polygyny (pink), promiscuous (black), and undefined or indeterminate (gray). Bars along the branch lengths represent gains or losses of each pure strategy. Nodes show maximum likelihood reconstruction estimate of ancestral mating systems as a proportion of each type. Arrows and associated dates indicate the most likely node of origin (circled nodes), defined as the node where the frequency of the strategy first rises above a likelihood of 0.33 and subsequently fixes with likelihood $>0.95$. 
heavily biased across the phylogeny: monogamous taxa occurred within 18 out of 31 families/subfamilies (58\%) for which we had data on mating system, and polygyny occurred in 17 of 31 families/subfamilies (55\%). Overall, our sampling is balanced in coverage despite being sparse in regard to total number of species.

We evaluated the hypothesis generated by our model that transitions to monogamy result in an increased diversification rate using a hidden state speciation and extinction (HiSSE) model. We compared the rate of speciation for monogamous species $\left(\lambda_{\text {mono }}\right)$ with the remaining mating systems $\left(\lambda_{\text {prom or polyg }}\right)$ to generate state-specific speciation rates for a binary character. In contrast to a standard binary state speciation and extinction (BiSSE) model, the hidden state speciation and extinction model includes hidden states to account for unmeasured traits that may influence the diversification rates for given states of an observed trait (Beaulieu and O’Meara 2016). As a consequence, a HiSSE approach estimates heterogeneity in diversification rates unrelated to the focal trait yet simultaneously accounts for the effects of the measured trait on diversification. A key advantage of HiSSE is that transition rates among states are estimated independently for the hidden and observed traits. In our analysis, we fit two BiSSElike models and five HiSSE models. We fit two BiSSE-like models, which included a null analysis to estimate diversification rates independent of the mating system and a model including the influence of mating system on diversification rates. Our HiSSE models included (1) a null model where character states evolve independently, (2) a full model allowing the estimation of diversification rates for mating system and a hidden trait, (3) a model to estimate the effects of monogamy and a hidden trait on diversification rates, and (4) two character-independent diversification models (CID-2 and CID-4). These models have the advantage of assuming that the evolution of a trait is independent of the diversification rate without requiring diversification rates to be constant (Beaulieu and O'Meara 2016). The CID-2 model has the same number of parameters as the BiSSE-like model, whereas the CID- 4 model has the equivalent number of parameters for a generalized HiSSE model. We used the diversitree (FitzJohn 2012) and hisse (Beaulieu and O'Meara 2016) packages in $\mathrm{R}$ to estimate the models of trait-dependent diversification.

The correlation between mating system and parental care was accomplished using a threshold model (Felsenstein 2012) and implemented using the threshBayes function in the phytools package (Revell 2012). We sampled 200,000 generations with a burn-in of 40,000 generations. We sampled every 500 trees to generate an estimate of the correlation between mating system and parental care. We used the HPDinterval function in the coda package (Plummer et al. 2006) to obtain the highest posterior dis- tribution interval for the correlation coefficient from the MCMC sampling.

\section{Support for Model Assumptions}

Our review of rodent mating systems supported the major assumptions of our model. The first set of assumptions concerns the existence and ancestral state of three genetically determined alternative strategies. First, mating behavior in at least some rodent species - and, indeed, other taxonomically distant species - can in part be traced to alternative alleles at key loci (Bester-Meredith et al. 1999; Young et al. 1999; Lim and Young 2004; Lim et al. 2004; Young and Wang 2004; Fink et al. 2006; Walum et al. 2008), as assumed by our behavioral genetics model of mating system evolution. Furthermore, we found that mating systems exhibited significant phylogenetic signal $(\lambda=0.754, P<.01)$, suggesting that the notion of an underlying genetic cause is likely.

Three lines of evidence suggest that alternative mating strategies exist in rodents. Territorial spacing within some promiscuous rodent species is consistent with territorial expectations of three mating strategies assumed in our model (monogamy, polygyny, sneak; table S3). Indeed, studies with detailed territory maps of promiscuous species show that some males control large territories with several females, other males control smaller nonoverlapping territories and single females, whereas others are wideranging without control of a territory (Maza et al. 1973; Scantlebury et al. 2008), corresponding to the three strategies modeled. Detailed behavioral data in a few species support the existence of within-population alternative strategies similar to those in our model (Bishop et al. 2004; Scantlebury et al. 2008; Mills et al. 2009), although data on fitness asymmetries among strategies (i.e., intransitivity) are still unknown for any rodent system. Intraspecific color polymorphism versus monomorphism identifies mating systems in reptiles (Sinervo and Lively 1996; Corl et al. 2010), birds (Lank et al. 1995), and damselflies (Svensson et al. 2005), so we searched for similar patterns in our rodent data set. In rodents, we found instances of segregating coat color polymorphism (including some trimorphic species) in mixed or promiscuous species $(N=18$; table S6), suggestive of alternative strategy markers, but we failed to document color polymorphism in any monogamous or polygynous taxa, which should be fixed for one strategy. Coat color patterns likely underestimate the prevalence of alternative strategy markers - which are more likely olfactory in rodents, given their heavy reliance on scent-but nonetheless suggest that alternative strategies are present in some rodent taxa.

Finally, estimates of ancestral character state transitions using maximum likelihood enabled us to quantify the 
probability of ancestral mating system states at each node and the number and age of independent mating system transitions in rodents (figs. 2, S3). A promiscuous mating system (i.e., multiple strategies) is ancestral (figs. 2, S3), as assumed in our model. Taken together, these lines of evidence suggest that our model assumption of genetically based alternative strategies is valid for the available rodent data.

The second set of assumptions involves the prevalence of recognition and paternal care behaviors. Both discrimination and filiative behavior, which rely on genic recognition to produce spatial clustering, are observed in vertebrates (Emlen and Wrege 1988; Russell and Hatchwell 2001; Krakauer 2005), including rodents (Bester-Meredith et al. 1999; Mateo 2003, 2004; Widdig 2007; Green et al. 2015), and can drive social interactions (Mateo 2004; Krakauer 2005; Hain and Neff 2006; Sinervo et al. 2006; Holmes and Mateo 2007; Widdig 2007). Kin recognition is tied to specific genes (e.g., arginine vasopressin) that also affect mating system, social relationships, and paternal care in some rodents (Bester-Meredith et al. 1999; Young et al. 1999; Marler et al. 2003; Lim et al. 2004; Young and Wang 2004; Nam et al. 2010; Ophir et al. 2012). The key assumption linking evolution of monogamy to paternal care was also confirmed in the phylogenetic data set for the subset of species with clear evidence of parental care patterns. The threshold test implemented using the threshBayes function in the phytools package (Revell 2012) found a strong association between monogamy and paternal care $(r=0.90$ (highest posterior density interval $=0.79-0.97)$, $P<.05$; fig. S4]. In our sample, all monogamous taxa exhibit paternal care. Some polygynous and mixed mating systems exhibit paternal care $(50 \%)$, and all $(N=7)$ of those that do are recently derived within ancient monogamous clades where genes for care in polygynous males could represent a vestige of ancestral monogamy. Some promiscuous mating systems exhibit care (21\%), as expected since they contain monogamy. Thus, model assumptions of genic recognition, biased settlement, and paternal care coupled with monogamy are valid for rodents.

\section{The Congruence of Model Outcomes and Empirical Patterns}

Patterns of evolutionary transitions in rodent mating systems are consistent with our model results that consider genetic mating strategies in the absence of variation in resource ecology. Most taxa are promiscuous (56\%, 161 taxa), as expected given the large parameter domain for competitive behaviors $(c, k, d)$ that maintain RPS cycles of three strategies when cooperative behaviors $(f, p)$ are weak (black areas in fig. S2) or mixed polygyny-sneak when discrimination behavior $(d)$ is absent (black areas in fig. 1). The next most common mating systems in rodents are monogamy and polygyny, two ESSs found in our model for higher levels of cooperative behaviors ( $f$, $p$; case 3 of simulation results). More taxa are monogamous than polygynous (72 vs. 45 species; sign test assuming 50:50; $P<.005)$, as observed in our model output, since polygyny as a pure ESS exists only in a thin parameter space where cooperative behaviors $(f, p)$ are high enough to eliminate sneak but not high enough to displace polygyny (red vs. blue areas in figs. 1, S1). Other potential mating systems (e.g., pure sneak, mixed sneak-monogamy) did not occur in our survey and were also not stable outcomes in our ESS model.

\section{Evolutionary Transitions between Mating Systems}

Our model showed that increases in the benefits of monogamous behaviors (filiative, paternal care) are largely responsible for transitions between mating system states (figs. 1, S1, S2). In our sample, many more rodent taxa are monogamous $(26 \%)$ relative to mammals in general (3\% [Kleiman 1977], 9\% [Lukas and Clutton-Brock 2013]) but similar to some other orders (29\% of primates and $16 \%$ of carnivores [Lukas and Clutton-Brock 2013]), and monogamy is present in most major rodent lineages (14 of 21; figs. 2, S3). Monogamy is also the most common unambiguous evolutionary transition from a promiscuous ancestor (we define unambiguous transition when a single strategy increases above $33 \%$ in likelihood analysis [Mooers and Schluter 1999], although probabilities are generally $>50 \%$ in such cases; $N=21$; figs. 2, S3) and more common than unambiguous evolutionary transitions to polygyny $(N=12)$. Our estimates of transitions among mating systems using a stochastic character mapping analysis suggest that evolutionary shifts from promiscuity to monogamy (20\%) were much more common than those from promiscuity to polygyny ( $8 \%$; figs. 3 , S5), as expected from our model, which shows a larger parameter space associated with monogamy than polygyny (red vs. blue areas in figs. 1, S1). If increases in monogamous behaviors facilitate the evolution of polygyny, as predicted by our model (increase in $f, p$ in figs. $1, \mathrm{~S} 1$ ), we would expect polygynous clades to be younger than monogamous ones. Transitions to monogamy are somewhat older than those to polygyny, although the difference is not significant (monogamy: mean age of origin $=14.1-3.1$ million years ago, $N=14$; polygyny: mean age of origin $=9.7-2.1$ million years ago, $N=5$; nested ANOVA, $P=.11$; fig. S3). Furthermore, we predict that polygyny should exist in clades where monogamy becomes more common since polygyny relies on monogamy to eliminate sneak for establishment as a pure ESS in our model (red areas as $f, p$ increase in figs. 1, S1). If we restrict analysis of mating system origins to clades 


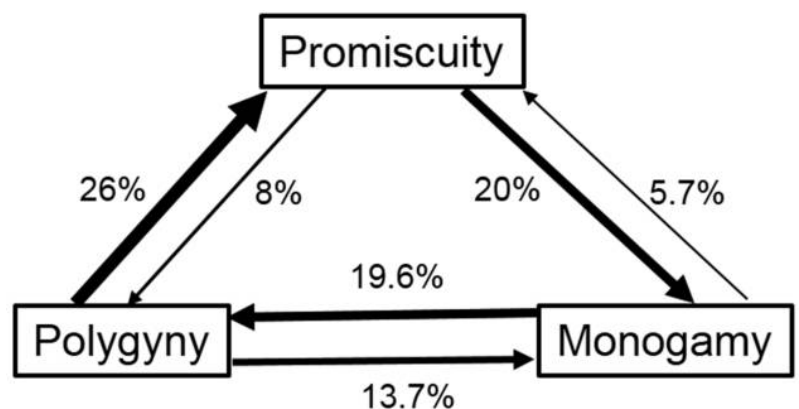

Figure 3: Frequency of transitions between mating system states estimated by stochastic character mapping reconstruction. The frequency of transitions from promiscuity to monogamy is greater than to polygyny, as predicted by our mating system model. Likewise, transitions from monogamy to polygyny are higher than the reverse, as predicted. Transitions back to promiscuity were not possible in our simple model but show up surprisingly frequently in the data. The stochastic character map phylogeny is shown in figure S5, available online.

with well-supported ancestral fixations of monogamy (e.g., nodes where likelihood of all other strategies are <0.05), then we can identify clades where polygyny is derived (fig. 2). By this criterion, there are eight independent fixations of monogamy, which outnumber the single independent fixation of polygyny, which is nested within a monogamous clade (fig. 2). Furthermore, transitions from monogamy to polygyny (19.6\%) are more common than from polygyny to monogamy (13.7\%; figs. 3; S5), as expected if increases in monogamous behaviors promote polygyny (red areas as $f$, $p$ increase in figs. $1, \mathrm{~S} 1$ ).

Mating system transitions should also involve rare or unstable coexistence of two mating systems according to our model. Some species showed mixed mating systems comprised of monogamy and polygyny (i.e., sneak lost, nine taxa), which was never an ESS in our simulations but does exist as a transitory state when monogamy eliminates sneak. Thus, mixed monogamy-polygyny could be a transient state before fixation to monogamy or polygyny. Alternatively, mixed mating species may reflect a contact zone between neighboring populations fixed for polygyny and monogamy. In either case, rarity of mixed mating systems in rodents is consistent with our model.

We also found mating system transitions in rodents not seen in the model results. Unambiguous transitions from pure monogamy (likelihood probability $>0.95$ ) back to promiscuity (one case) or to polygyny or mixed systems (seven cases) suggest that mating system reversals occur. For example, ancestral Bathygeridae are monogamous, yet Fukomys hottentotus hottentotus is promiscuous (fig. 2; Bishop et al. 2004), reflecting a reinvasion of polygyny and sneak. Behavioral and genetic paternity patterns in
$F$. h. hottentotus include wide-ranging polygynous males, monogamous mate-guarding males, and diminutive sneaker males (Bishop et al. 2004), resembling other RPS systems (Sinervo and Calsbeek 2006; Sinervo et al. 2006, 2007). Such patterns in mating system transitions could reflect either uncertainty in the loss of mating systems (ancestral probability $<0.05$ ) or the appearance of new mating systems lost in the ancestor (novel mutation). The stochastic character mapping analysis likewise identified transitions that were not possible in our model formulation, including those from monogamy to promiscuity $(5.6 \%)$ or from polygyny to promiscuity (26\%), which was surprisingly common (figs. 3; S5). Future models that would allow for the reintroduction of lost strategies would be particularly informative on this issue. These patterns of mating system transitions back to multistrategy states evoke an evolutionary cycle of RPS intransitivity (Sinervo and Lively 1996), but at a phylogenetic level if it reflects reinvasion of new genetic strategies that were lost on previous evolutionary transitions.

\section{Effects on Speciation Rates}

Genetic mating system games can enhance speciation rates if diversification in one mating system exceeds those in others. Indeed, our model results suggest that increased monogamous behaviors $(f, p)$ can lead to bifurcation of promiscuous taxa into monogamous or polygynous taxa. Such bifurcations can occur through rapid divergence between populations as monogamous behaviors increase (fig. 1; thin red band of polygyny vs. blue band of monogamy with little change in $f$ and $p$ when $d>2$ ) or when different populations with the same degree of monogamous behaviors have different initial allele frequencies (fig. S1; boxes with both blue and red for the same values of $p$, $d)$. We tested for the effects of mating system on diversification rates using HiSSE. The BiSSE-like model revealed that monogamous lineages had higher speciation rates $\left(\lambda_{\text {mono }}=14.95\right)$ than lineages with promiscuous or other mating systems $\left(\lambda_{\text {prom }}=3.101\right)$, suggesting that monogamous lineages diversified $\sim 4.8$ times faster than lineages with promiscuous mating systems. We contrasted results of the BiSSE model with those of a hidden states model using a model selection approach based on AIC and AIC model weights (table 1). The full model HiSSE (includes hidden states and independent transition rates) outperformed the remaining six models (two BiSSE and four other HiSSE). Lineages that evolved monogamous mating systems had higher diversification rates than those with promiscuity or polygyny as a result of higher speciation rates and lower overall turnover ( $\lambda$ and $\tau$ in table 2; fig. S6). Moreover, promiscuous mating systems had higher observed extinction rates than monogamous mating systems 
Table 1: Results from binary state speciation and extinction (BiSSE)-like and hidden state speciation and extinction (HiSSE) analyses of trait-dependent diversification

\begin{tabular}{lcrl}
\hline Model & \multicolumn{1}{c}{ AIC } & \multicolumn{1}{c}{$\Delta$ AIC } & AIC weight \\
\hline HiSSE: & & & \\
Full & $\mathbf{- 2 0 5 . 2 2}$ & $\mathbf{. 0 0}$ & $\mathbf{. 9 7 6}$ \\
Monogamy & -196.55 & 8.67 & .011 \\
CID4 & -168.76 & 36.46 & .000000012 \\
Null & -139.01 & 66.21 & $4.08 \mathrm{E}-15$ \\
CID2 & -139.00 & 66.21 & $4.08 \mathrm{E}-15$ \\
BiSSE: & & & \\
Full & -168.30 & 36.91 & .0000000094 \\
Null & -139.91 & 65.31 & $6.41 \mathrm{E}-15$ \\
\hline
\end{tabular}

Note: Values presented are Akaike information criterion (AIC) scores, differences ( $\triangle \mathrm{AIC}$ ), and AIC weights for each model comparing diversification rates of monogamous versus promiscuous mating systems. Boldface indicates the best fit model.

( $\mu$ in table 2). Notably, the full model also showed the influence of a hidden state on diversification of rodents. Interestingly, the influence of the hidden state appears to affect promiscuous clades to a greater extent than monogamous clades. Furthermore, net turnover appeared to be higher in promiscuous lineages than monogamous lineages $(\tau$ in table 2; fig. S6). A higher speciation rate in monogamous clades from our HiSSE analysis should lead to more taxa from monogamous versus promiscuous clades. Indeed, a sister taxon comparison shows that transitions to monogamy in rodent clades yields a 4.74 -fold greater number of species than sister clades retaining a promiscuous mating system (Wilcoxon signed rank test on log(species in sister clades): $S_{10}=27.5, P=.002$; fig. 2 ; table S7).

Our model simulations show that a rise in monogamous behaviors (increasing $f, p$ ) in a more monogamous ancestor could lead to both monogamous and polygynous descendent species with little change in monogamous behaviors (rapid transitions to red and blue with increased $f$ and $p$ in figs. $1, \mathrm{~S} 1$ ) more often than from a promiscuous ancestor (i.e., low monogamous behaviors $f$, $p$ ), which should lead to a higher speciation rate in monogamous lineages. We tested this prediction by randomizing character states across the tree topology (including nodal values based on ancestral reconstructions), preserving the frequency of each mating system and observed an average of 8.1 pairs of descendent taxa where monogamy was sister to either polygyny or a polygyny-monogamy mixed mating system. Less than $1 / 200$ randomizations $(P=.005)$ had as many bifurcating pairs containing monogamy and polygyny as we observed in our data set $(N=17$; figs. 2, S3), suggesting that monogamy and polygyny arise as sister taxa twice as often as expected by chance alone. Two mechanisms might lead to this pattern. First, monogamy enhances invasion of polygyny because weak monogamous behaviors (slight increases in $p$ and $f$ shift from promiscuity in black to polygyny in red in figs. 1, S1) facilitate fixation of polygyny as a pure ESS, as predicted by our model. Likewise, if monogamous behaviors become less developed $(p$ and $f$ decrease; start frequencies with high monogamy but low $p$, $f$ in fig. S1), polygyny can invade monogamy. Second, monogamy and polygyny could result from socially mediated speciation (Hochberg et al. 2003). Social traits in monogamous lineages when hybridized with polygynous lineages may yield hybrids with depressed fitness (Gill 1984), reinforcing speciation and fixation of different mating systems in adjacent populations. This process could be accelerated if genes for filiative behavior in males have pleiotropic effects on female mate choice (Sinervo et al. 2006), thereby leading to rapid reproductive isolation between individuals with or without monogamy genes.

\section{Genetic Mechanisms of Mating System Transitions}

Rapid shifts between genetically based mating systems rely on simple mutations that impact cooperative behaviors $(f$, $p)$, regardless of the surrounding resource distribution. Evolutionary transitions between monogamy and polygyny in rodents have been linked to a point mutation in a vasopressin receptor gene (V1aR; Lim and Young 2004; Lim et al. 2004; Fink et al. 2006), and this gene is also linked to increased paternal behavior and reduced aggression (i.e., filiative behavior) in monogamous species (BesterMeredith et al. 1999). Such mutations would provide a mechanism for the simultaneous rapid evolution of increased care and filiative behaviors needed for bifurcation into monogamy or polygyny and potentially lead to speciation. Moreover, pleiotropic effects of V1aR could lead to rapid evolution of more advanced forms of sociality through enhanced genic clustering, fidelity, care, and cooperation, which might explain why highly social species in rodents (e.g., mole rats and marmots) originate from monogamous lineages.

The cooperate-care strategy we equate with monogamy is a form of genic recognition that acts through filiative and paternal care behaviors and conflicts with polygynous

Table 2: Estimated rates of speciation $(\lambda)$, extinction $(\mu)$, and net turnover $(\tau)$ derived from the full hidden state speciation and extinction model

\begin{tabular}{lrlr}
\hline & $\lambda$ & \multicolumn{1}{c}{$\mu$} & $t$ \\
\hline Promiscuity: & & & \\
Observed & 3.35 & .04 & 3.26 \\
Hidden & 9.70 & $1.99 \mathrm{E}-08$ & 13.41 \\
Monogamy: & & & \\
Observed & 30.33 & $6.33 \mathrm{E}-08$ & 2.23 \\
Hidden & 2.04 & 1.40 & 13.49 \\
\hline
\end{tabular}


strategies. Work on genic recognition in mammals has shown patterns of genomic imprinting present in polygynous/promiscuous species but absent in monogamous sister taxa (e.g., Peromyscus polionotus vs. Peromyseus maniculatus, Mus spretus vs. Mus spicelegus; Haig 1996; Burt and Trivers 2006). Experimental crosses between sister taxa yield hybrid unfitness as a result of mismatches in imprinted loci of sires and counterstrategy imprinted loci of dams (Burt and Trivers 2006). Genomic imprinting may enhance speciation of monogamous and polygynous/promiscuous taxa (Gill 1984) due to alternative alleles for genic male care and contribute to accelerated bifurcation into monogamous and polygynous sister taxa. We predict that newly evolved genomic imprints should exist in the 23 independent transitions from ancient monogamy to promiscuity/polygyny.

We modeled complex behaviors driven by a single gene, and such a formulation could have important consequences for speciation. While a single gene with multiple effects facilitates theoretical analysis, there is also building evidence for such systems in the empirical literature. For example, genetic analysis of ruffs that show alternative male strategies shows that a large inversion has created a supergene that drives male color, mating behavior, and aggression (Küpper et al. 2016). Alternatively, a single gene can have pleiotropic effects on multiple behaviors, as has been found in cooperative behavior of slime molds (Queller et al. 2003; Foster et al. 2004), and is a likely mechanism underlying the association between hormone receptor genes in rodents $(\mathrm{V} 1 \mathrm{aR})$ and multiple mating and prosocial behaviors (Wang et al. 1994; Bester-Meredith et al. 1999; Lim et al. 2004; Young and Wang 2004; Albers 2012). Finally, such effects could be due to multiple genes that are tightly coupled through linkage disequilibrium despite being scattered across the genome, as described in lizards (Sinervo et al. 2006). If the behaviors and their underlying genes segregate in both males and females, then mate choice for specific behavioral types could generate correlational selection and build up such linkage (Alonzo and Sinervo 2001; Sinervo et al. 2008). Interestingly, such multiple effects that we describe here resemble magic traits explored in the speciation literature as a critical component generating rapid speciation in adjacent or sympatric populations (reviewed in Servedio et al. 2011). While magic traits describe traits that couple phenotypic traits for mate choice with fitness traits related to ecology, the genes we describe couple social behavior with reproductive success as a consequence of social selection (West-Eberhard 1983; Lyon and Montgomerie 2012), also referred to as socially mediated speciation (Hochberg et al. 2003). Indeed, expanding the definition of magic traits to include such socially selected cases could greatly increase the contexts under which speciation with gene flow is expected to arise.

\section{Contrasting Genetic and Resource Ecological Mating System Models}

The genetic mating system model we propose here both contrasts and complements classic resource ecological mating system models (Verner and Willson 1966; Orians 1969; Emlen and Oring 1977; Davies 1991; Shuster and Wade 2003; Lukas and Clutton-Brock 2013). In contrast to resource ecological models, our genetic model is able to make predictions about evolutionary transitions between mating system states and the likely impact of such mating system transitions on speciation rates. In both cases, our model predictions are consistent with empirical data from rodents. Furthermore, the genetic model could provide an explanation for cases where mating system transitions do not match resource ecology transitions because of phylogenetic inertia when mating system is conserved despite resource distribution change or when mating system shifts despite resource ecology remaining static. Our survey of rodent mating systems contains examples of different populations of a single species with either different $(N=14)$ or the same $(N=4)$ mating system, and comparisons of the resource distributions of these populations could help identify cases where the genetic model provides added insight relative to the resource distribution ecological model.

While there is increasing evidence for a genetic basis of mating behavior (Wang et al. 1998; Lim et al. 2004; Young and Wang 2004; Walum et al. 2008; Corl et al. 2010; Küpper et al. 2016; Lamichhaney et al. 2016), there are cases where resource ecology likely has a direct influence on a mating system (Emlen and Oring 1977; Shuster and Wade 2003), suggesting that both mechanisms could interact. From this perspective, resource distribution shifts could explain reversals in mating system states (e.g., monogamous or polygynous back to promiscuous) not predicted by our genetic model through shifts in the costs and benefits of space use or cooperative behaviors. Indeed, phenotypic plasticity is common for behavioral strategies, and the real question might be how resource ecology and genetics interact to shape mating system state. Addition of fine-scale resource and environmental ecological data to our rodent mating system data set would allow an evaluation of the explanatory power of each mechanism in predicting mating system evolution and phylogenetic signal and would be a fruitful first step in this direction. Likewise, models for different genetic mechanisms underlying behavioral strategies (e.g., plasticity, dominance, heterozygote advantage; Moulherat et al. 2017) could broaden our understanding of behavioral genetic influences on mating system evolution, now that we have demonstrated the ability of a simple codominant genetic model to predict empirical patterns of mating system evolution in rodents. 


\section{Broader Implications}

Genetically based social strategies in our model and identified in rodents (Young and Wang 2004) have broad implications for population ecology since territorial strategies (polygyny, monogamy, sneak) use space differently and have varying intensities of density regulation against their own strategy (table S1A; see also Sinervo et al. 2007). Density cycles in rodent species could be due to social competition among alternative strategies (Chitty 1996) in promiscuous taxa. Indeed, female density cycles have been identified in lizards with alternative mating strategies (Sinervo et al. 2000) because the strategies that evolve in females involve progeny size and progeny quantity. Likewise, densitydependent alternative reproductive strategies identified in the promiscuous bank vole (Mappes et al. 2008) could drive population density cycles. We also found three examples of coat color morphs in promiscuous rodent species that similarly show population density cycles, which might be expected when coat color genes have pleiotropic effects on social behavior (Broadhurst et al. 1974) and life history (table S6).

The strength of our hypothesis is the integration of multiple factors (e.g., territory spacing patterns, mating systems transitions, social speciation, genomic imprinting, color polymorphism, and density cycles) that jointly support a genic model of frequency-dependent competition to drive mating system evolution. Indeed, alternative strategies generate mating system variation and predicts evolutionary transitions among mating system states irrespective of resource ecology. While resource distribution and environmental ecology have some influence on the benefits of social behaviors, genetically based mating strategies themselves are sufficient to drive mating system evolution. Our model should generalize to other vertebrates. For example, many fish species exhibit alternative strategies that include parental and sneaker males or three strategies (Oliveira et al. 2008). In trimorphic bluegill sunfish, male care (nest guarding) is associated with genic recognition of progeny (Neff 2003) by polygynous rather than monogamous males, with evidence of RPS dynamics (Friedman and Sinervo 2016). Care-giving males form colonies where mutual defense (cooperation) enhances successful fry development (Côté and Gross 1993) by repulsion of sneakers and predators. Trimorphic alternative mating strategies consistent with an RPS game are also documented in a broad array of other taxa, including bacteria, flowers, crustaceans, insects, lizards, and birds (Shuster and Wade 2003; Sinervo and Calsbeek 2006; Sinervo et al. 2007; Oliveira et al. 2008; Friedman and Sinervo 2016). As such, frequencydependent competition among alternative strategies could facilitate mating system evolution and speciation in many taxa through intrinsic effects of behavioral genetics.

\section{Acknowledgments}

We thank J. Bradbury, A. Corl, L. Lancaster, M. Mulks, M. Morris, A. Uy, J. Bronstein, and two anonymous reviewers for comments as well as J. F. LeGalliard, A. McAdam, M. MacManes, and P. Wandeler for sharing data. Support was provided by the CNRS; National Science Foundation grants to B.S., A. McAdam, and D.B.M.; the Université Paul Sabatier (B.S., D.B.M.); and Agence Nationale de la Recherche (ANR) grant JCJC-NetSelect (A.S.C.). This work is part of the Laboratoire d'Excellence entitled TULIP (ANR-10-LABX-41) and the Institute for Advanced Studies in Toulouse through ANR grant ANR-17-EURE-0010 (Investissements d'Avenir program) for A.S.C.

Statement of authorship: All authors contributed equally to the research. B.S., A.S.C., and D.B.M. collectively designed research. B.S. and A.S.C. constructed the model, and A.S.C. ran simulations. All authors collected data from the literature. D.B.M. and B.S. conducted phylogenetic comparative analyses. All authors wrote and edited the manuscript.

\section{Data and Code Availability}

All data used in analyses come from the literature; both data and references are provided in table format in the supplemental material (table S2).

\section{Literature Cited}

Albers, H. E. 2012. The regulation of social recognition, social communication and aggression: vasopressin in the social behavior neural network. Hormones and Behavior 61:283-292.

Alonzo, S. H. 2007. Conflict between the sexes and cooperation within a sex can alter classic predictions of mating systems theory. Evolutionary Ecology Research 9:145-156.

- 2010. Social and coevolutionary feedbacks between mating and parental investment. Trends in Ecology and Evolution 25:99-108.

Alonzo, S. H., and B. Sinervo. 2001. Mate choice games, contextdependent good genes, and genetic cycles in the side-blotched lizard, Uta stansburiana. Behavioral Ecology and Sociobiology 49:176-186.

Alonzo, S. H., M. Taborsky, and P. Wirtz. 2000. Male alternative reproductive behaviours in a Mediterranean wrasse, Symphodus ocellatus: evidence from otoliths for multiple life-history pathways. Evolutionary Ecology Research 2:997-1007.

Barreto, W. P., F. M. D. Marquitti, and M. A. M. de Aguiar. 2017. A genetic approach to the rock-paper-scissors game. Journal of Theoretical Biology 421:146-152.

Beaulieu, J. M., and B. C. O’Meara. 2016. Detecting hidden diversification shifts in models of trait-dependent speciation and extinction. Systematic Biology 65:583-601.

Bester-Meredith, J. K., L. J. Young, and C. A. Marler. 1999. Species differences in paternal behavior and aggression in Peromyscus and their associations with vasopressin immunoreactivity and receptors. Hormones and Behavior 36:25-38. 
Bishop, J. M., J. U. M. Jarvis, A. C. Spinks, N. C. Bennett, and C. O'Ryan. 2004. Molecular insight into patterns of colony composition and paternity in the common mole-rat Cryptomys hottentotus hottentotus. Molecular Ecology 13:1217-1229.

Bollback, J. P. 2006. SIMMAP: stochastic character mapping of discrete traits on phylogenies. BMC Bioinformatics 7:88.

Bomze, I. M. 1983. Lotka-Volterra equation and replicator dynamics: a two-dimensional classification. Biological Cybernetics 48:201211.

Broadhurst, P. L., D. W. Fulker, and J. Wilcock. 1974. Behavioral genetics. Annual Review of Psychology 25:389-415.

Burt, A., and R. Trivers. 2006. Genes in conflict: the biology of selfish genetic elements. Harvard University Press, Cambridge, MA.

Chitty, D. 1996. Do lemmings commit suicide? beautiful hypotheses and ugly facts. Oxford University Press, New York.

Cordero, A., S. Carbone, and C. Utzeri. 1998. Mating opportunities and mating costs are reduced in androchrome female damselflies, Ischnura elegans (Odonata). Animal Behaviour 55:185-197.

Corl, A., A. R. Davis, S. R. Kuchta, and B. Sinervo. 2010. Selective loss of polymorphic mating types is associated with rapid phenotypic evolution during morphic speciation. Proceedings of the National Academv of Sciences of the USA 107:4254-4259.

Côté, I. M., and M. R. Gross. 1993. Reduced disease in offspring: a benefit of coloniality in sunfish. Behavioral Ecology and Sociobiology 33:269-274.

Davies, N. B. 1991. Mating systems. Pages 263-294 in J. R. Krebs and D. N. B, eds. Behavioral ecology: an evolutionary approach. Vol. 3. 3rd ed. Blackwell Scientific, Oxford.

Dillard, J. R., and D. F. Westneat. 2016. Disentangling the correlated evolution of monogamy and cooperation. Trends in Ecology and Evolution 31:503-513.

Emlen, S., and L. Oring. 1977. Ecology, sexual selection, and the evolution of mating systems. Science 197:215-222.

Emlen, S. T., and P. H. Wrege. 1988. The role of kinship in helping decisions among white-fronted bee-eaters. Behavioral Ecology and Sociobiology 23:305-315.

Fabre, P.-H., L. Hautier, D. Dimitrov, and E. J. P Douzery. 2012. A glimpse on the pattern of rodent diversification: a phylogenetic approach. BMC Evolutionary Biology 12:88.

Felsenstein, J. 2012. A comparative method for both discrete and continuous characters using the threshold model. American Naturalist 179:145-156.

Ferguson, J. N., J. M. Aldag, T. R. Insel, and L. J. Young. 2001. Oxytocin in the medial amygdala is essential for social recognition in the mouse. Journal of Neuroscience 21:8278-8285.

Fink, S., L. Excoffier, and G. Heckel. 2006. Mammalian monogamy is not controlled by a single gene. Proceedings of the National Academy of Sciences of the USA 103:10956-10960.

FitzJohn, R. G. 2012. Diversitree: comparative phylogenetic analyses of diversification in R. Methods in Ecology and Evolution 3:1084-1092.

Foster, K. R., G. Shaulsky, J. E. Strassmann, D. C. Queller, and C. R. L. Thompson. 2004. Pleiotropy as a mechanism to stabilize cooperation. Nature 431:693-696.

Frean, M., and E. R. Abraham. 2001. Rock-scissors-paper and the survival of the weakest. Proceedings of the Roval Societv B 268:13231327.

Friedman, D., J. Magnani, D. Paranjpe, and B. Sinervo. 2017. Evolutionary games, climate and the generation of diversity. PLoS ONE 12:e0184052.
Friedman, D., and B. Sinervo. 2016. Evolutionary games in natural, social, and virtual worlds. Oxford University Press, New York.

Gill, A. E. 1984. Partial reproductive isolation of subspecies of the California vole, Microtus californicus. Genetica 52/53:105-117.

Gomes, B. V., D. M. Guimarães, D. Szczupak, and K. Neves. 2018. Female dispersion and sex ratios interact in the evolution of mating behavior: a computational model. Scientific Reports 8:2467.

Green, J. P., A. M. Holmes, A. J. Davidson, S. Paterson, P. Stockley, R. J. Beynon, and J. L. Hurst. 2015. The genetic basis of kin recognition in a cooperatively breeding mammal. Current Biology 25:2631-2641.

Haig, D. 1996. Gestational drive and the green-bearded placenta. Proceedings of the National Academv of Sciences of the USA 93:6547-6551.

Hain, T. J. A., and B. D. Neff. 2006. Promiscuity drives self-referent kin recognition. Current Biology 16:1807-1811.

Harmon, L. J., J. T. Weir, C. D. Brock, R. E. Glor, and W. Challenger. 2008. GEIGER: investigating evolutionary radiations. Bioinformatics 24:129-131.

Hochberg, M. E., B. Sinervo, and S. P. Brown. 2003. Socially mediated speciation. Evolution 57:154-158.

Holmes, W. G., and J. M. Mateo. 2007. Kin recognition in rodents: issues and evidence. Pages 216-250 in J. O. Wolff and P. W. Sherman, eds. Rodent societies: an ecological and evolutionary perspective. University of Chicago Press, Chicago.

Houston, A. I., T. Székely, and J. M. McNamara. 2013. The parental investment models of Maynard Smith: a retrospective and prospective view. Animal Behaviour 86:667-674.

Jukema, J., and T. Piersma. 2006. Permanent female mimics in a lekking shorebird. Biology Letters 2:161-164.

Jungwirth, A., and R. A. Johnstone. 2018. Multiple evolutionary routes to monogamy: modeling the coevolution of mating decisions and parental investment. American Naturalist 193:E29-E40.

Kleiman, D. G. 1977. Monogamy in mammals. Quarterly Review of Biology 52:39-69.

Klug, H. 2018. Why monogamy? a review of potential ultimate drivers. Frontiers in Ecology and Evolution 6:30.

Knafo, A., S. Israel, A. Darvasi, R. Bachner-Melman, F. Uzefovsky, L. Cohen, E. Feldman, et al. 2008. Individual differences in allocation of funds in the dictator game associated with length of the arginine vasopressin 1a receptor RS3 promoter region and correlation between RS3 length and hippocampal mRNA. Genes. Brain, and Behavior 7:266-275.

Kokko, H., and M. D. Jennions. 2008. Parental investment, sexual selection and sex ratios. Journal of Evolutionary Biology 21:919-948.

Komers, P. E., and P. N. Brotherton. 1997. Female space use is the best predictor of monogamy in mammals. Proceedings of the Roval Society B 264:1261-1270.

Krakauer, A. 2005. Kin selection and cooperative courtship in wild turkeys. Nature 434:69-72.

Küpper, C., M. Stocks, J. E. Risse, N. Dos Remedios, L. L. Farrell, S. B. McRae, T. C. Morgan, et al. 2016. A supergene determines highly divergent male reproductive morphs in the ruff. Nature Genetics 48:79-83.

Kvarnemo, C. 2018. Why do some animals mate with one partner rather than many? a review of causes and consequences of monogamy. Biological Reviews 93:1795-1812.

Lamichhaney, S., G. Fan, F. Widemo, U. Gunnarsson, D. S. Thalmann, M. P. Hoeppner, S. Kerje, et al. 2016. Structural genomic changes underlie alternative reproductive strategies in the ruff (Philomachus pugnax). Nature Genetics 48:84-88. 
Lank, D. B., C. M. Smith, O. Hanotte, T. Burke, and F. Cooke. 1995 Genetic polymorphism for alternative mating behavior in lekking male ruff Philomachus pugnax. Nature 378:59-62.

Lim, M. M., Z. Wang, D. E. Olazabal, X. Ren, E. F. Terwilliger, and L. J. Young. 2004. Enhanced partner preference in a promiscuous species by manipulating the expression of a single gene. Nature 429:754-757.

Lim, M. M., and L. J. Young. 2004. Vasopressin-dependent neural circuits underlying pair bond formation in the monogamous prairie vole. Neuroscience 125:35-45.

Lukas, D., and T. H. Clutton-Brock. 2013. The evolution of social monogamy in mammals. Science 341:526-530.

Lyon, B. E., and R. Montgomerie. 2012. Sexual selection is a form of social selection. Philosophical Transactions of the Roval Society B 367:2266-2273.

Mappes, T., M. Koivula, E. Koskela, T. Oksanen, T. Savolainen, and B. Sinervo. 2008. Frequency and density-dependent selection on lifehistory strategies: a field experiment. PLoS ONE 3:e1687.

Marler, C. A., J. K. Bester-Meredith, and B. C. Trainor. 2003. Paternal behavior and aggression: endocrine mechanisms and nongenomic transmission of behavior. Pages 263-323 in P. Slater, J. Rosenblatt, C. Snowdon, and T. Roper, eds. Advances in the study of behavior. Vol 32. Elsevier, Amsterdam,

Mateo, J. M. 2003. Kin recognition in ground squirrels and other rodents. Lournal of Mammalogy 84:1163-1181.

- 2004. Recognition systems and biological organization: the perception component of social recognition. Annales Zoologici Fennici 41:729-745.

Maynard Smith, J. 1977. Parental investment: a prospective analysis. Animal Behaviour 25:1-9.

1982. Evolution and the theory of games. Cambridge University Press, Cambridge.

Maza, B. G., N. R. French, and A. P. Aschwanden. 1973. Home range dynamics in a population of Heteromyid rodents. Journa of Mammalogy 54:405-425.

Mills, S. C., A. Grapputo, I. Jokinen, E. Koskela, T. Mappes, T. A. Oksanen, and T. Poikonen. 2009. Testosterone-mediated effects on fitness-related phenotypic traits and fitness. American Naturalist 173:475-487.

Mooers, A. Ø., and D. Schluter. 1999. Reconstructing ancestor states with maximum likelihood: support for one-and two-rate models. Svstematic Biology 48:623-633.

Moulherat, S., A. Chaine, A. Mangin, F. Aubret, B. Sinervo, and J. Clobert. 2017. The roles of plasticity versus dominance in maintaining polymorphism in mating strategies. Scientific Reports 7:15939.

Nam, K.-B., M. Simeoni, S. P. Sharp, and B. J. Hatchwell. 2010. Kinship affects investment by helpers in a cooperatively breeding bird. Proceedings of the Roval Society B 277:3299-3306.

Neff, B. D. 2003. Paternity and condition affect cannibalistic behavior in nest-tending bluegill sunfish. Behavioral Ecology and Sociobiology 54:377-384.

Okhovat, M., A. Berrio, G. Wallace, A. G. Ophir, and S. M. Phelps. 2015. Sexual fidelity trade-offs promote regulatory variation in the prairie vole brain. Science 350:1371-1374.

Oliveira, R., M. Taborsky, and H. J. Brockmann. 2008. Alternative reproductive tactics: an integrative approach. Cambridge University Press, New York.

Ophir, A. G., A. Gessel, D.-J. Zheng, and S. M. Phelps. 2012. Oxytocin receptor density is associated with male mating tactics and social monogamy. Hormones and Behavior 61:445-453.
Ophir, A. G., J. O. Wolff, and S. M. Phelps. 2008. Variation in neural V1aR predicts sexual fidelity and space use among male prairie voles in semi-natural settings. Proceedings of the National Academv of Sciences of the USA 105:1249-1254.

Orians, G. H. 1969. On the evolution of mating systems in birds and mammals. American Naturalist 103:589-603.

Paradis, E., J. Claude, and K. Strimmer. 2004. APE: analyses of phylogenetics and evolution in R language. Bioinformatics 20:289-290.

Plummer, M., N. Best, K. Cowles, and K. Vines. 2006. CODA: convergence diagnosis and output analysis for MCMC. R News 6:7-11.

Ptak, S. E., and M. Lachmann. 2003. On the evolution of polygyny: a theoretical examination of the polygyny threshold model. Behavioral Ecology 14:201-211.

Queller, D. C., E. Ponte, S. Bozzaro, and J. E. Strassmann. 2003. Singlegene greenbeard effects in the social amoeba Dictyostelium discoideum. Science 299:105-106.

Ranta, E., and V. Kaitala. 1999. Punishment of polygyny. Proceedings of the Roval Societv B 266:2337-2341.

R Development Core Team. 2018. R: a language and environment for statistical computing. R Foundation for Statistical Computing, Vienna.

Revell, L. J. 2012. phytools: an R package for phylogenetic comparative biology (and other things). Methods in Ecology and Evolution 3:217-223.

Russell, A. F., and B. J. Hatchwell. 2001. Experimental evidence for kin-biased helping in a cooperatively breeding vertebrate. Proceedings of the Roval Society B 268:2169-2174.

Salisbury, B. A., and J. Kim. 2001. Ancestral state estimation and taxon sampling density. Systematic Biology 50:557-564.

Sandell, M., and O. Liberg. 1992. Roamers and stayers: a model on male mating tactics and mating systems. American Naturalist 139:177-189.

Scantlebury, M., J. M. Waterman, and N. C. Bennett. 2008. Alternative reproductive tactics in male Cape ground squirrels Xerus inauris. Physiology and Behavior 94:359-367.

Schradin, C. 2008. Differences in prolactin levels between three alternative male reproductive tactics in striped mice (Rhabdomys pumilio). Proceedings of the Roval Society B 275:1047-1052.

Schradin, C., and N. Pillay. 2005a. Intraspecific variation in the spatial and social organization of the African striped mouse. Lournal of Mammalogy 86:99-107.

Servedio, M. R., G. S. V. Doorn, M. Kopp, A. M. Frame, and P. Nosil. 2011. Magic traits in speciation: 'magic' but not rare? Trends in Ecology and Evolution 26:389-397.

Shuster, S. M., and C. Sassaman. 1996. Genetic interaction between male strategy and sex ratio in a marine isopod. Nature 388:373377.

Shuster, S., and M. Wade. 2003. Mating systems and strategies. Princeton University Press, Princeton, NJ.

Sinervo, B. 2001. Runaway social games, genetic cycles driven by alternative male and female strategies, and the origin of morphs. Genetica 112:417-434.

Sinervo, B., and R. Calsbeek. 2006. The developmental, physiological, neural, and genetical causes and consequences of frequencydependent selection in the wild. Annual Review of Ecology, Evolution, and Systematics 37:581-610.

Sinervo, B., A. Chaine, J. Clobert, R. Calsbeek, L. Hazard, L. Lancaster, A. G. McAdam, et al. 2006. Self-recognition, color signals, and cycles of greenbeard mutualism and altruism. Proceedings of the National Academy of Sciences of the USA 103:7372-7377. 
Sinervo, B., J. Clobert, D. B. Miles, A. McAdam, and L. T Lancaster. 2008. The role of pleiotropy vs signaller-receiver gene epistasis in life history trade-offs: dissecting the genomic architecture of organismal design in social systems. Heredity 101: 197-211.

Sinervo, B., B. Heulin, Y. Surget-Groba, J. Clobert, D. B. Miles, A. Corl, A. Chaine, et al. 2007. Models of density-dependent genic selection and a new rock-paper-scissors social system. American Naturalist 170:663-680.

Sinervo, B., and C. M. Lively. 1996. The rock-paper-scissors game and the evolution of alternative male strategies. Nature 380:240-243.

Sinervo, B., E. Svensson, and T. Comendant. 2000. Density cycles and an offspring quantity and quality game driven by natural selection. Nature 406:985-988.

Svensson, E. I., J. Abbott, and R. Hardling. 2005. Female polymorphism, frequency dependence, and rapid evolutionary dynamics in natural populations. American Naturalist 165:567-576.

Temeles, E. J. 1994. The role of neighbors in territorial systems: when are they "dear enemies." Animal Behaviour 47:339-350.

Vehrencamp, S. L., and J. W. Bradbury. 1984. Mating systems and ecology. Pages 251-278 in J. R. Krebs and N. B. Davies, eds. Behavioral ecology: an evolutionary approach. 2nd ed. Sinauer, Sunderland, MA.

Verner, J., and M. F. Willson. 1966. The influence of habitats on mating systems of North American passerine birds. Ecology 47:143-147.

Wakano, J. Y., and Y. Ihara. 2005. Evolution of male parental care and female multiple mating: game-theoretical and two-locus diploid models. American Naturalist 166:E32-E44.

Walum, H., L. Westberg, S. Henningsson, J. M. Neiderhiser, D. Reiss, W. Igl, J. M. Ganiban, et al. 2008. Genetic variation in the vasopressin receptor 1a gene (AVPR1A) associates with pair-bonding behavior in humans. Proceedings of the National Academv of Sciences of the USA 105:14153-14156.

Wang, Z., C. F. Ferris, and G. J. De Vries. 1994. Role of septal vasopressin innervation in paternal behavior in prairie voles (Microtus ochrogaster). Proceedings of the National Academy of Sciences of the USA 91:400-404.

Wang, Z. X., L. J. Young, G. J. De Vries, and T. R. Insel. 1998. Voles and vasopressin: a review of molecular, cellular, and behavioral studies of pair bonding and paternal behaviors. Progress in Brain Research 119:483-499.

Waterman, J. 2007. Male mating strategies in rodents. Pages 27-41 in J. O. Wolff and P. W. Sherman, eds. Rodent societies: an ecological and evolutionary perspective. University of Chicago Press, Chicago.

West-Eberhard, M. J. 1983. Sexual selection, social competition, and speciation. Quarterly Review of Biology 58:155-183.

Widdig, A. 2007. Paternal kin discrimination: the evidence and likely mechanisms. Biological Reviews of the Cambridge Philosophical Society 82:319-334.

Wright, S. 1968. Evolution and the genetics of populations. University of Chicago Press, Chicago.

Young, L. J. 1999. Oxcytocin and vasopressin receptors and speciestypical social behaviors. Hormones and Behavior 36:212-221.

Young, L. J., R. Nilsen, K. G. Waymire, G. R. MacGregor, and T. R. Insel. 1999. Increased affiliative response to vasopressin in mice expressing the V1a receptor from a monogamous vole. Nature 400:766-768.

Young, L. J., and Z. Wang. 2004. The neurobiology of pair bonding. Nature Neuroscience 7:1048-1054.

\section{References Cited Only in the Online Enhancements}

Adler, G. H. 2011. Spacing patterns and social mating systems of echimyid rodents. Journal of Mammalogy 92:31-38.

Adler, G. H., M. Endries, and S. Piotter. 1997. Spacing patterns within populations of a tropical forest rodent, Proechimys semispinosus, on five Panamanian islands. Journal of Zoology 241:43-53.

Adrian, O., I. Brockmann, C. Hohoff, and N. Sachser. 2005. Paternal behaviour in wild guinea pigs: a comparative study in three closely related species with different social and mating systems. Journal of Zoology 265:97-105.

Agrell, J. 1997. Experimental testing of female mating strategies in microtine rodents. Seventh International Theriological Congress, Acapulco.

Agren, G., Q. Zhou, and W. Zhong. 1989. Ecology and social behaviour of Mongolian gerbils, Meriones unguiculatus, at Xilinhot, Inner Mongolia, China. Animal Behaviour 37:11-27.

Aguilera, M. M. 1999. Population ecology of Proechimys guairae (Rodentia: Echimyidae). Journal of Mammalogy 80:487-498.

Airoldi, J.-P. 1976a. The burrow system of the fossorial form of the water vole, Arvicola terrestris scherman Shaw (Mammalia, Rodentia). International Journal of Mammalian Biology 41:23-42.

- 1976b. Capture and recapture experiments in the water vole, Arvicola terrestris scherman Shaw (Mammalia, Rodentia). Terre et Vie 30:31-51.

. $1976 c$. Study through capture and recapture of a population of water voles, Arvicola terrestris scherman Shaw (Mammalia, Rodentia). Terre et Vie 32:3-45.

Aliaga-Rossel, E., R. W. Kays, and J. M. V. Fragoso. 2008. Home-range use by the Central American agouti (Dasyprocta punctata) on Barro Colorado Island, Panama. Journal of Tropical Ecology 24:367-374.

Allainé, D. 2000. Sociality, mating system and reproductive skew in marmots: evidence and hypotheses. Behavioural Processes 51:21-34.

Allainé, D., and F. Theuriau. 2004. Is there an optimal number of helpers in Alpine marmot family groups? Behavioral Ecology 15:916-924.

Andreassen, H. P., and S. Bondrup-Nielsen. 1991. Home range size and activity of the wood lemming, Myopus schisticolor. Holarctic Ecology 14:138-141.

Anstee, S. D., J. D. Roberts, and J. E. O'Shea. 1997. Social structure and patterns of movement of the Western pebble-mound mouse, Pseudomys chapmani, at Marandoo, Western Australia. Wildlife Research 24:295-305.

Antolin, M. F., B. Van Horne, M. D. Berger, A. K. Holloway, J. L. Roach, and R. D. Weeks. 2001. Effective population size and genetic structure of a Piute ground squirrel (Spermophilus mollis) population. Canadian Journal of Zoology 79:26-34.

Arjo, W. M., R. E. Huenefeld, and D. L. Nolte. 2007. Mountain beaver home ranges, habitat use, and population dynamics in Washington. Canadian Journal of Zoology 85:328-337.

Armitage, K. B. 1986. Individuality, social behavior, and reproductive success in yellow-bellied marmots. Ecology 67:1186-1193.

Asher, M., E. S. de Oliveira, and N. Sachser. 2004. Social system and spatial organization of wild guinea pigs (Cavia aperea) in a natural population. Journal of Mammalogy 85:788-796.

Axenovich, T. I., P. S. D’Andrea, F. Fernandes, C. R. Bonvicino, I. V. Zorkoltseva, and P. M. Borodin. 2004. Inheritance of white head spotting in natural populations of South American water rat (Nectomys squamipes Rodentia: Sigmodontinae). Lournal of Heredity 95:76-80. 
Baba, M., T. Doi, and Y. Ono. 1982. Home range utilization and nocturnal activity of the giant flying squirrel, Petaurista leucogenys. Japanese Journal of Ecology 32:189-198.

Baker, R. J., K. D. Makova, and R. K. Chesser. 1999. Microsatellites indicate a high frequency of multiple paternity in Apodemus (Rodentia). Molecular Ecology 8:107-111.

Barrett, G. W. 1976. Occurrence of a wild population of extreme dilute meadow voles. Journal of Heredity 67:109-110.

Bartmann, S., and G. Gerlach. 2001. Multiple paternity and similar variance in reproductive success of male and female wood mice (Apodemus sylvaticus) housed in an enclosure. Ethology 107:889899.

Batzli, G. O., and H. Henttonen. 1993. Home range and social organization of the singing vole (Microtus miurus). Journal of Mammalogy 74:868-878.

Baudoin, C., N. Busquet, F. S. Dobson, G. Gheusi, C. Feron, J.-L. Durand, G. Heth, et al. 2005. Male-female associations and female olfactory neurogenesis with pair bonding in Mus spicilegus. Biological Journal of the Linnean Society 84:323-334.

Bazhan, N. M., T. V. Iakovleva, and E. N. Makarova. 1996. Reproduction of the water voles (Arvicola terrestris) polymorphic for the aguti locus. Genetika 32:1125-1130.

Bazhan, N. M., T. V. Yakovleva, and E. N. Makarova. 1999. Agouti locus may influence reproduction under food deprivation in the water vole (Arvicola terrestris). Journal of Experimental Zoology 283:573-579.

Beg, M. A. 1969. Habitats, food habits, and population dynamics of the red-tailed chipmunk, Eutamias ruficaudus, in western Montana. PhD diss. University of Montana, Missoula.

Begall, S., H. Burda, and M. Gallardo. 1999. Reproduction, postnatal development, and growth of social coruros, Spalacopus cyanus (Rodentia: Octodontidae), from Chile. Journal of Mammalogy 80:210217.

Behrends, P., M. Daly, and M. I. Wilson. 1989. Range use patterns and spatial relationships of Merriam's kangaroo rats (Dipodomys merriami). Behaviour 96:187-209.

Belk, M. C., and H. D. Smith. 1991. Ammospermophilus leucurus. Mammalian Species 368:1-8.

Bennett, N. C., and C. G. Faulkes. 2000. African mole-rats: ecology and eusociality. Cambridge University Press, Cambridge.

Bennett, N. C., J. U. M. Jarvis, and F. P. D. Cotterill. 1994. The colony structure and reproductive biology of the afrotropical Mashona mole-rat, Cryptomys darlingi. Journal of Zoology 234:477-487.

Bergallo, H. G. 1995. Comparative life-history characteristics of two species of rats, Proechimys iheringi and Oryzomys intermedius, in an Atlantic forest of Brazil. Mammalia 59:51-64.

Bergstrom, B. J. 1988. Home ranges of three species of chipmunks (Tamias) as assessed by radiotelemetry and grid trapping. Lournal of Mammalogy 69:190-193.

Berteaux, D., J. Bêty, E. Rengifo, and J.-M. Bergeron. 1999. Multiple paternity in meadow voles (Microtus pennsylvanicus): investigating the role of the female. Behavioral Ecology and Sociobiology 45:283-291.

Bertolino, S., N. Cordero, and I. Currado. 2003. Home ranges and habitat use of the garden dormouse (Eliomys quercinus) in a mountain habitat in summer. Acta Zoologica Hungarica 49:11-18.

Bertolino, S., C. Viano, and I. Currado. 2001. Population dynamics, breeding patterns and spatial use of the garden dormouse (Eliomys quercinus) in an Alpine habitat. Journal of Zoology 253:513521.
Best, T. L. 1993. Tamias ruficaudus. Mammalian Species 452:1-7. 1995. Spermophilus mohavensis. Mammalian Species 509:1-7.

Best, T. L., S. L. Burt, and J. L. Bartig. 1994. Tamias quadrivittatus. Mammalian Species 466:1-7.

Best, T. L., and S. Riedel. 1995. Sciurus arizonensis. Mammalian Species 496:1-5.

Birdsall, D. A., and D. Nash. 1973. Occurrence of successful multiple insemination of females in natural populations of deer mice (Peromyseus maniculatus). Evolution 27:106-110.

Blair, W. F. 1940. Home ranges and populations of the jumping mouse. American Midland Naturalist 23:244-250.

. 1941. Observations on the life history of Baiomys taylori subater. Journal of Mammalogy 22:378-383.

.1942. Size of home range and notes on life history of the woodland deer mouse and eastern chipmunk in northern Michigan. Journal of Mammalogy 23:27-36.

Blumstein, D. T., and K. B. Armitage. 1999. Cooperative breeding in marmots. Oikos 84:369-382.

Boellstorff, D. E., D. H. Owings, M. C. T. Penedo, and M. J. Hersek. 1994. Reproductive behaviour and multiple paternity of California ground squirrels. Animal Behaviour 47:10571064

Boggs, C. L. 1974. Social ecology of the white-throated woodrat (Neotoma albigula) in Arizona. PhD diss. Arizona State University, Tempe.

Bonaventura, S. M., F. O. Kravetz, and O. V. Suárez. 1992. The relationship between food availability, space use and territoriality in Akodon azarae. Mammalia 56:407-416.

Boonsong, L., J. A. McNeely, and J. Marshall. 1988. Mammals of Thailand. Association for the Conservation of Wildlife, Bangkok.

Boonstra, R., X. Xia, and L. Pavone. 1993. Mating system of the meadow vole, Microtus pennsylvanicus. Behavioral Ecology 4:8389.

Booth, W., W. I. Montgomery, and P. A. Prodohl. 2007. Polyandry by wood mice in natural populations. Journal of Zoology 273:176-182.

Bowers, M. A., K. Gregario, C. J. Brame, S. F. Matter, and J. L. D. Jr. 1996. Use of space and habitats by meadow voles at the home range, patch and landscape scales. Oecologia 105:107-115.

Boyce, C. C. K., and J. L. Boyce. 1988. Population biology of Microtus arvalis. III. Regulation of numbers and breeding dispersion of females. Journal of Animal Ecology 57:737-754.

Branch, L. C. 1993a. Intergroup and intragroup spacing in the plains vizcacha, Lagostomus maximus. ournal of Mammalogy 74:890900.

1993b. Social organization and mating system of the plains viscacha. Journal of Zoology 229:473-491.

Breed, W. G., and M. Adams. 1992. Breeding systems of the spinifex hopping mouse (Notomys alexis) and plains rats (Pseudomys australis): a test of multiple paternity within the laboratory. Australian Journal of Zoology 40:13-20.

Brooks, R. J. 1993. Dynamics of home range in collard lemmings. Pages 355-386 in N. C. Stenseth and R. A. Ims, eds. The biology of lemmings. Linnean Symposium Series. Academic Press, London.

Bryja, J., H. Patzenhauerová, T. Albrecht, L. Mošanský, M. Stanko, and P. Stopka. 2008. Varying levels of female promiscuity in four Apodemus mice species. Behavioral Ecology and Sociobiology 63:251-260.

Bubela, T., and D. Happold. 1993. The social organisation and mating system of an Australian subalpine rodent, the broad-toothed rat, Mastacomys fuscus Thomas. Wildlife Research 20:405-417. 
Buckner, C. H. 1957. Home range of Synaptomys cooperi. Journal of Mammalogy 38:132.

Burda, H., R. L. Honeycutt, S. Begall, O. Locker-Grütjen, and A. Scharff. 2000. Are naked and common mole-rats eusocial and if so, why? Behavioral Ecology and Sociobiology 47:293-303.

Burland, T. M., N. C. Bennett, J. U. M. Jarvis, and C. G. Faulkes. 2004. Colony structure and parentage in wild colonies of co-operatively breeding Damaraland mole-rats suggest incest avoidance alone may not maintain reproductive skew. Molecular Ecology 13:2371-2379.

Burns, G. R. 1981. Population dynamics of island populations of subarctic Clethrionomys rutilus. Canadian Journal of Zoology 59:21152122.

Burt, S. L., and J. L. Bartig. 1994. Tamias quadrivittatus. Mammalian Species 466:1-7.

Busher, P. 2007. Social organization and monogamy in the beaver. Pages 280-290 in J. O. Wolff and P. W. Sherman, eds. Rodent societies: an ecological and evolutionary perspective. University of Chicago Press, Chicago.

Cameron, G. N., and S. R. Spencer. 1985. Assessment of space-use patterns in the hispid cotton rat (Sigmodon hispidus). Oecologia 68:133-139.

Cassaing, J. 1984. Interactions intra- et inter-spécifiques chez les souris sauvages du Midi de la France, Mus musculus domesticus et $M$. spretus: conséquences sur la compétition entre les espèces. Biological Behavior 9 281-293.

—. 1990. Aspects évolutifs liés au mode d'intégration de l'individu dans la société : une approche "relationnelle " du système social dans les populations de souris européennes. $\mathrm{PhD}$ diss. University of Montpellier-2.

Cassaing, J., and H. Croset. 1985. Organisation spatiale, compétition et dynamique des populations de Souris (Mus spretus Lataste et Mus musculus domesticus Rutty) du Midi de la France. Mammalian Biology 50:271-284.

Cassaing, J., and F. Isaac. 2007. Pair bonding in the wild mouse Mus spretus: inference on the mating system. Comptes Rendus Biologie 330:828-836.

Channing, A. 1984. Ecology of the namtap Gruphiurus ocularis (Rodentia: Gliridae) in the Cedarberg, South Africa. South African Journal of Zoology 19:144-149.

Cheprakov, M., N. Evdokimov, and N. Glotov. 2005. Inheritance of coat color in the mole vole (Ellobius talpinus Pallas). Russian Journal of Genetics 41:1281-1286.

Clark, F. 1935. Coat color in the meadow vole. $\underline{\text { ournal of Heredity }}$ 29:265-266.

Clark, M. M., D. Desousad, D. Vonk, and B. G. Galef. 1997. Parenting and potency: alternative routes to reproductive success in male Mongolian gerbils. Animal Behaviour 54:635-642.

Clark, M. M., and B. G. Galef. 1999. A testosterone-mediated trade-off between parental and sexual effort in male Mongolian gerbils (Meriones unguiculatus). Journal of Comparative Psychology 113:388-395.

- 2000. Why some male Mongolian gerbils may help at the nest: testosterone, asexuality and alloparenting. Animal Behaviour 59:801-806.

Cockburn, A. 1981. Population processes of the silky desert mouse Pseudomus apodemoides Rodentia in mature heathlands. Australian Wildlife Research 8:499-514.

Collins, H. H. 1923. Studies of the pelage phases and of the nature of color variations in mice of the genus Peromyscus. Journal of Experimental Zoology 38:45-107.
Conditt, S. A., and D. O. Ribble. 1997. Social organization of Neotoma micropus, the Southern Plains woodrat. American Midland Naturalist 137:290-297.

Connor, P. F. 1959. The bog lemming Synaptomys cooperi in southern New Jersey. Publication of the Museum of Michigan State University Biology Series 1:161-248.

Corbet, N. U., and R. J. V. Aarde. 1996. Social organization and space use in the Cape porcupine in a Southern African savanna. African Journal of Ecology 34:1-14.

Curtis, J. T. 2002. A blond coat color variation in Meadow vole (Microtus pennsylvanicus). Journal of Heredity 93:209-210.

Cushing, B. S., J. O. Martin, L. J. Young, and C. S. Carter. 2001. The effects of peptides on partner preference formation are predicted by habitat in prairie voles. Hormones and Behavior 39:48-58.

Cutrera, A. P., C. D. Antinuchi, M. S. Mora, and A. I. Vassallo. 2006. Home-range and activity patterns of the South American subterranean rodent Ctenomys talarum. Lournal of Mammalogy 87:11831191.

Davies, K. C., and J. U. M. Jarvis. 1986. The burrow systems and burrowing dynamics of the mole-rats Bathyergus suillus and Cryptomys hottentotus in the fynbos of the south-western Cape, South Africa. Journal of Zoology 209:125-147.

Day, Y.-T. 1988. Subspecies and geographic variation of Petaurista alborufus and Petaurista petaurista Rodentia Sciuridae. Journal of Taiwan Museum 41:75-84.

Dewsbury, D. A. 1972. Patterns of copulatory behaviour in male mammals. Quarterly Review of Biology 47:1-33.

- 1981. An exercise in the prediction of monogamy in the field from laboratory data on 42 species of muroid rodents. Biologist 63:138-162.

Dewsbury, D. A., and A. W. Hodges. 1987. Copulatory behavior and related phenomena in spiny mice (Acomys cahirinus) and hopping mice (Notomys alexis). Journal of Mammalogy 68:49-57.

Dobson, F. S., and C. Baudoin. 2002. Experimental tests of spatial association and kinship in monogamous mice (Mus spicilegus) and polygynous mice (Mus musculus domesticus). Canadian Journal of Zoology 80:980-986.

Dobson, S. 1982. Competition for mates and predominant juvenile male dispersal in mammals. Animal Behaviour 30:1183-1192.

Dodson, K. M., W. D. Dawson, S. O. Van Ooteghem, B. S. Cushing, and G. R. Haigh. 1987. Platinum coat color locus in the deer mouse. Journal of Heredity 78:183-186.

Drabek, C. M. 1973. Home range and daily activity of the roundtailed ground squirrel, Spermophilus tereticaudus neglectus. American Midland Naturalist 89:287-293.

Drożdż, A. 1971. Inheritance and frequency of new color mutations in the bank vole, Clethrionomys glareolus. Journal of Mammalogy 52:625-628.

Dubost, G. 1988. Ecology and social life of the red acouchy, Myoprocta exilis; comparison with the orange-rumped agouti, Dasyprocta leporina. \ournal of Zoology 214:107-123.

Dunford, C. 1977a. Behavioral limitations of round-tailed ground squirrel density. Ecology 58:1254-1268.

. 1977b. Kin selection for ground squirrel alarm calls. American Naturalist 58:782-785.

Ebensperger, L. A., M. J. Hurtado, and C. León. 2007. An experimental examination of the consequences of communal versus solitary breeding on maternal condition and the early postnatal growth and survival of degu, Octodon degus, pups. Animal Behaviour 73: 185-194. 
Ebensperger, L. A., P. Taraborelli, S. M. Giannoni, M. J. Hurtado C. León, and F. Bozinovic. 2006. Nest and space use in a highland population of the southern mountain cavy (Microcavia australis). Journal of Mammalogy 87:834-840.

Eccard, J. A., J. Meyer, and J. Sundell. 2004. Space use, circadian activity pattern, and mating system of the nocturnal tree rat Thallomys nigricaudaI. Iournal of Mammalogy 85:440-445.

Edelman, A. J., and J. L. Koprowski. 2006. Seasonal changes in home ranges of Abert's squirrels: impact of mating season. Canadian Lournal of Zoology 84:404-411.

Egoscue, H. J. 1960. Laboratory and field studies of the northern grasshopper mouse. Journal of Mammalogy 41:99-110.

Eisenberg, J. F. 1963. The behavior of heteromyid rodents. University of California Publications in Zoology 69.

. 1975. The behavior patterns of desert rodents. Pages 189224 in I. Prakash and P. K. Ghosh, eds. Rodents in desert environments. Junk, Hague.

Endries, M. J., and G. H. Adler. 2005. Spacing patterns of a tropical forest rodent, the spiny rat (Proechimys semispinosus), in Panama Journal of Zoology 265:147-155.

Engstrom, M. D., and R. C. Dowler. 1981. Field observations of mating behaviour in Dipodomys ordii. Journal of Mammalogy 62:384-386.

Erpino, M. 1968. Copulatory behavior in the white-tailed prairie dog. American Midland Naturalist 79:250-251.

Eshelman, B. D., and C. S. Sonnemann. 2000. Spermophilus armatus. Mammalian Species 637:1-6.

Evdokimov, N. G. 2001. Population ecology of the common mole vole (Ellobius tulpinus Pallas). Ekaterinburg, Yekaterinburg

. 2005. Comparative analysis of coat color morphs in a polymorphic population of the northern mole vole. Russian Journal of Ecology 36:400-407.

Evsikov, V., G. Kokenova, P. Zadubrovskii, O. Potapova, and M. Potapov. 2006. Monogamy as one of the ways of realization of the adaptive potential in mammals as exemplified by the steppe lemming Lagurus lagurus Pallas. Dokladv Biological Sciences 411:501-503.

Evsikov, V. I., G. G. Nazarova, and M. A. Potapov. 1997. Geneticecological monitoring of a cyclic population of water vole Arvicola terrestris L. in the south of western Siberia. Russian Journal of Genetics 33:963-972.

Fadao, T., W. Tingzheng, and Z. Yajun. 2000. Inbreeding avoidance and mate choice in the mandarin vole (Microtus mandarinus). Canadian Journal of Zoology 78:2119-2125.

Farentinos, R. C. 1972. Social dominance and mating activity in the tassel-eared squirrel (Sciurus aberti ferreus). Animal Behaviour 20:316-326.

- 1980. Sexual solicitation of subordinate males by female tassel-eared squirrels (Sciurus aberti). Journal of Mammalogy 61:337-341.

Foltz, D. W. 1981. Genetic evidence for long-term monogamy in a small rodent, Peromyscus polionotus. American Naturalist 117:665675.

Foltz, D. W., and J. L. Hoogland. 1981. Analysis of the mating system in the black-tailed prairie dog (Cynomys ludovicianus) by likelihood of paternity. Journal of Mammalogy 62:706-712.

Foltz, D. W., and P. L. Schwagmeyer. 1989. Sperm competition in the thirteen-lined ground squirrel: differential fertilization success under field conditions. American Naturalist 133:257-265.

Frank, D. H., and E. J. Heske. 1992. Seasonal changes in space use patterns in the southern grasshopper mouse, Onychomys torridus torridus. Journal of Mammalogy 73:292-298.
Frank, F., and K. Zimmerman. 1957. Farbungs-mutationen der Feldmaus [Microtus arvalis (Pall.)]. International Journal of Mammalian Biology 22:87-100.

Fukuta, K., K. Imamura, and N. Goto. 1991. Pink-eyed dilution, a coat color mutation in the Japanese field vole (Microtus montebelli). jikken Dobutsu 40:375-379.

Galaktionov, Y. K., and V. I. Faleev. 2000. Water vole (Arvicola terrestris L.) coat color variation in connection with population dynamics. Proceedings of the Russian Academy of Sciences 372:276-278.

Gentile, R., P. S. D'Andrea, and R. Cerqueira. 1997. Home ranges of Philander frenata and Akodon cursor in a Brazilian restinga (coastal shrubland). Mastozoología Neotropical 4:105-112.

Gershenson, S. 1945a. Evolutionary studies on the distribution and dynamics of melanism in the hamster (Cricetus cricetus L.). I. Distribution of black hamsters in the Ukrainian and Bashkirian Soviet Socialist Republics (U.S.S.R.). Genetics 30:207-232.

. 1945b. Evolutionary studies on the distribution and dynamics of melanism in the hamster (Cricetus cricetus L.). II. Seasonal and annual changes in the frequency of black hamsters. Genetics 30:233-251.

Getty, T. 1981. Structure and dynamics of chipmunk home range. Journal of Mammalogy 62:726-737.

Getz, L. L., and C. S. Carter. 1980. Social behavior in Microtus ochrogaster populations. Biologist 62:56-69.

Getz, L. L., and J. E. Hofmann. 1986. Social organization in freeliving prairie voles, Microtus ochrogaster. Behavioral Ecology and Sociobiology 18:275-282.

Gill, A. E. 1976. White spotting in the California vole. Heredity 37:113-128.

- 1977a. Maintenance of polymorphism in an island population of the California vole, Microtus californicus. Evolution 31:512525.

. 1977b. Polymorphism in an island population of the California vole, Microtus californicus. Heredity 38:1-11.

- 1981. Morphological features and reproduction of Perognathus and Peromyscus on northern islands in the Gulf of California. American Midland Naturalist 106:192-196.

Goossens, B., L. Graziani, L. P. Waits, E. Farand, S. Magnolon, J. Coulon, M. C. Bel, et al. 1998. Extra-pair paternity in the monogamous Alpine marmot revealed by nuclear DNA microsatellite analysis. Behavioral Ecology and Sociobiology 43:281-288.

Gouat, P. 1988. Étude socioécologique de trois espaces de rongeurs Ctenodactylides d'Algérie. Thèse d'État, Université de Lyon, Claude Bernard.

Gouat, P., K. Katona, and C. Poteaux. 2003. Is the socio-spatial distribution of mound-building mice, Mus spicilegus, compatible with a monogamous mating system? Mammalia 67:15-24.

Granjon, L., and J.-M. Duplantier. 1993. Social structure in synanthropic populations of a murid rodent Mastomys natalensis in Senegal. Acta Theriologica 38:39-47.

Gray, S. J., J. L. Hurst, R. Stidworthy, J. Smith, R. Preston, and R. MacDougall. 1998. Microhabitat and spatial dispersion of the grassland mouse (Mus spretus Lataste). Journal of Zoology 246:299308.

Graziani, R. N., and E. A. Lacey. 2004. A molecular analysis of the mating system of the Patagonian tuco-tuco (Ctenomys haigi). American Society of Mammalogists Meeting.

Gromov, V. S. 1997. The spatial relationships and social structure of gerbils in the genus Meriones (Gerbillinae, Rodentia). Zhurnal Obshchei Biologii 58:35-54. 
- 2005. Types of spatial and ethological structure of rodent populations. Zoologicheskii Zhurnal 84:1003-1014.

Gromov, V. S., B. R. Krasnov, and G. I. Shenbrot. 2000. Space use in Wagner's gerbil Gerbillus dasyurus in the Negev Highlands, Israel. Acta Theriologica 45:175-182.

Gromov, V. S., and A. V. Tchabovsky. 1995. On spatial structure of settlements of tamarisk gerbils (Meriones tamariscinus Pall.) during the non-reproductive period in Southern Kalmykia. Zoologicheskii Zhurnal 74:134-140.

Gubernick, D. J., and J. R. Alberts. 1987. The biparental care system of the California mouse, Peromyscus californicus. Journal of Comparative Psychology 101:169-177.

Gubernick, D. J., and J. C. Nordby. 1993. Mechanisms of sexual fidelity in the monogamous California mouse, Peromyscus californicus Behavioral Ecology and Sociobiology 32:211-219.

Gubernick, D. J., and T. Teferi. 2000. Adaptive significance of male parental care in a monogamous mammal. Proceedings of the Roval Society B 267:147-150.

Gubernick, D. J., S. Wright, and R. E. Brown. 1993. The significance of father's presence for offspring survival in the monogamous California mouse, Peromyscus californicus. Animal Behaviour 46:539546.

Guichón, M. L., M. Borgnia, C. F. Righi, G. H. Cassini, and M. H. Cassini. 2003. Social behavior and group formation in the coypu (Myocastor coypus) in the Argentinean pampas. Lournal of Mammalogy 84:254-262.

Guillotin, M. 1982. Rythmes d'activite et remimes alimentaires de Proechimys cuvieri et d'Oryzomys capito velutinus (Rodentia) en forêt guyanaise. Revue Ecologie (Terre et la Vie) 36:337-381.

Hance, J. 1969. Pseudobrown, a mutant in the oldfield mouse, Peromyscus polionotus. Bulletin of the South Carolina Academy of Sciences 31:42-43.

Hanken, J., and P. W. Sherman. 1981. Multiple paternity in Belding's ground squirrel litters. Science 212:351-353.

Hansen, R. M. 1957. Development of young varying lemmings ( $D i-$ crostonyx). Arctic 10:105-117.

Hanski, I. K., P. C. Stevens, P. Ihalempiä, and V. Selonen. 2000 Home-range size, movements, and nest-site use in the Siberian flying squirrel, Pteromys volans. Journal of Mammalogy 81:798-809.

Happold, M. 1976. Social behaviour of the conilurine rodents (Muridae) of Australia. Zeitschrift für Tierpsychologie 40:113-182.

Harris, D. B., and D. W. MacDonald. 2007. Population ecology of the endemic rodent Nesoryzomys swarthi in the tropical desert of the Galapagos islands. Journal of Mammalogy 88:208-219.

Hart, E. B., M. C. Belk, E. Jordan, and M. W. Gonzalez. 2004. Zapus princeps. Mammalian Species 749:1-7.

Haynie, M. L., R. A. Van den Bussche, and J. L. Hoogland. 2003. Parentage, multiple paternity, and breeding success in Gunnison's and Utah prairie dogs. Journal of Mammalogy 84:1244-1253.

Herr, J., and F. Rosell. 2004. Use of space and movement patterns in monogamous adult Eurasian beavers (Castor fiber). Lournal of Zoology 262:257-264.

Herrera, E. A., and D. W. MacDonald. 1993. Aggression, dominance, and mating success among capybara males (Hydrochaeris hydrochaeris). Behavioral Ecology 4:114-119.

Heske, E. J. 1987. Spatial structuring and dispersal in a high density population of the California vole, Microtus californicus. Holarctic Ecology 56:585-596.

Heske, E. J., and P. M. Jensen. 1993. Social structure in Lemmus lemmus during the breeding season. Pages 387-396 in N. C. Stenseth and R. A. Ims, eds. The biology of lemmings. Linnean Symposium Series. Academic Press, London.

Heske, E. J., and R. S. Ostfeld. 1990. Sexual dimorphism in size, relative size of testes, and mating systems in North American voles. Journal of Mammalogy 71:510-519.

Heske, E. J., G. Shenbrot, and K. Rogovin. 1995. Spatial organization of Stylodipus telum (Dipodidae, Rodentia) in Dagestan, Russia. Journal of Mammalogy 76:800-808.

Hohoff, C., K. Solmsdorff, P. Löttker, K. Kemme, J. Epplen, T. Cooper, and N. Sachser. 2002. Monogamy in a new species of wild guinea pigs (Galea sp.). Naturwissenschaften 89:462465.

Holt, D. W., M. T. Maples, and C. Savok. 2003. Black color morph of the brown lemming, Lemmus trimucronatus $=L$. sibiricus. Canadian Field-Naturalist 117:466-468.

Hoogland, J. L. 1981. The evolution of coloniality in white-tailed and black-tailed prairie dogs (Sciuridae: Cynomys leucurus and C. ludovicianus). Ecology 62:252-272.

Hoogland, J. L., and D. W. Foltz. 1982. Variance in male and female reproductive success in a harem-polygynous mammal, the blacktailed prairie dog (Sciuridae: Cynomys ludovicianus). Behavioral Ecology and Sociobiology 11:155-163.

Horner, B. E. 1947. Parental care of young mice of the genus Peromyscus. Journal of Mammalogy 28:31-36.

Horner, B. E., and J. M. Taylor. 1969. Paternal behavior in Rattus fuscipes. Journal of Mammalogy 50:803-805.

Huber, S., E. Millesi, and J. P. Dittami. 2002. Paternal effort and its relation to mating success in the European ground squirrel. Animal Behaviour 63:157-164.

Huck, U., R. Lisk, J. Allison, and C. Van Dongen. 1986. Determinants of reproductive success in the golden hamster. V. Social dominance and mating strategies under semi-natural conditions. Animal Behaviour 34:971-989.

Huminski, S. 1963. New colour mutation (ruby) in the Microtus ar valis (Pallas, 1779) and its inheritance. Acta Theriologica 7:321332.

Hurst, J. L., S. Hall, R. Roberts, and C. Christian. 1996. Social organization in the aboriginal house mouse, Mus spretus Lataste: behavioural mechanisms underlying the spatial dispersion of competitors. Animal Behaviour 51:327-344.

Hurst, J. L., L. Hayden, M. Kingston, R. Luck, and K. Sorensen. 1994. Response of the aboriginal house mouse Mus spretus Lataste to tunnels bearing the odours of conspecifics. Animal Behaviour 48:1219-1229.

Ims, R. A. 1987. Responses in spatial organization and behaviour to manipulations of the food resource in the vole Clethrionomys rufocanus. Journal of Animal Ecology 56:585-596.

Ims, R. A., S. Bondrup-Nielsen, R. Fredriksson, and K. Fredga. 1993. Habitat use and spatial distribution of the wood lemming, Myopus schisticolor. Pages 509-518 in N. C. Stenseth and R. A. Ims, eds. Biology of lemmings. Academic Press, London.

Innes, S., and D. Lavigne. 1979. Comparative energetics of coat colour polymorphs in the eastern grey squirrel, Sciurus carolinensis. Canadian Journal of Zoology 57:585-592.

Ishibashi, Y., S. Abe, and M. C. Yoshida. 1992. DNA fingerprinting of grey red-backed voles Clethrionomys rufocanus bedfordiae. Journal of the Mammalogical Society of Japan 17:19-26.

Iwasa, M. A. 2004. A note on aberrant pelage colors in a wild population of the gray red-backed vole Clethrionomys rufocanus bedfordiae in Hokkaido. Mammal Study 29:93-95. 
Jackson, T. P. 1999. The social organization and breeding system of Brants' whistling rat (Parotomys brantsii). Journal of Zoology 247:323-331.

Jannett, F. J. 1978. The density-dependent formation of extended maternal families of the montane vole, Microtus montanus nanus. Behavioral Ecology and Sociobiology 3:245-263.

- 1980. Social dynamics of the montane vole, Microtus montanus, as a paradigm. Biologist 62:3-19.

- 1981. Sex ratios in high density populations of the montane vole, Microtus montanus, and the behavior of territorial males. Behavioral Ecology and Sociobiology 8:297-307.

. 1982. Nesting patterns of adult voles, Microtus montanus, in field populations. Journal of Mammalogy 63:495-498.

Janse van Rensburg, L., N. C. Bennett, M. van der Merwe, A. S. Schoeman, and J. Brinders. 2003. Are non-reproductive male highveld mole-rats, Cryptomys hottentotus pretoriae physiologically suppressed while in the confines of the natal colony? Journal of Zoology 260:73-78.

Jeppsson, B. 1986. Mating by pregnant water voles (Arvicola terrestris): a strategy to counter infanticide by males? Behavioral Ecology and Sociobiology 19:293-296.

Johnson, K. 1981. Social organization in a colony of rock squirrels (Spermophilus variegatus, Sciuridae). Southwestern Naturalist 26:237-242.

Jones, W. T. 1989. Dispersal distance and the range of nightly movements in Merriam's kangaroo rats. Journal of Mammalogy 70:27-34.

- 1993. The social systems of heteromyid rodents. Pages 575595 in H. H. Genoways and J. H. Brown, eds. Biology of the Heteromyidae. American Society of Mammalogists, Stillwater, OK.

Juskaitis, R. 1997. Ranging and movement of the common dormouse in Lithuania. Acta Theriologica 42:113-122.

Kalcounis- Rüppell, M. C., and D. O. Ribble. 2007. A phylogenetic analysis of the breeding systems in Neotomine-Peromyscine rodents. Pages 68-85 in J. O. Wolff and P. W. Sherman, eds. Rodent societies: ecological and evolutionary approaches. University of Chicago Press, Chicago.

Kawata, M. 1985. Mating system and reproductive success in a spring population of the red-backed vole, Clethrionomys rufocanus bedfordiae. Oikos 45:181-190.

1988. Mating success, spatial organization, and male characteristics in experimental field populations of the red-backed vole Clethrionomys rufocanus bedfordiae. Iournal of Animal Ecology 57:217-235.

Keeler, C. E., and H. D. King. 1942. Multiple effects of coat color genes in the Norway rat, with special reference to temperament and domestication. Journal of Comparative Physiology and Psychology 34:241-250.

Keil, A., J. T. Epplen, and N. Sachser. 1999. Reproductive success of males in the promiscuous-mating yellow-toothed cavy (Galea musteloides). Journal of Mammalogy 80:1257-1263.

Kelly, P. A. 1989. Population ecology and social organization of duskyfooted woodrats, Neotoma fuscipes. $\mathrm{PhD}$ diss. University of California, Berkeley.

Kenagy, G. J., and S. C. Trombulak. 1986. Size and function of mammalian testes in relation to body size. Journal of Mammalogy 67:122.

Kiltie, R. A. 1992. Tests of hypotheses on predation as a factor maintaining polymorphic melanism in coastalplain fox squirrels (Sciurus niger L.). Biological Journal of the Linnean Society 45:17-37.
King, W. J., and J. O. Murie. 1985. Temporal overlap of female kin in Columbian ground squirrels (Spermophilus columbianus). Behavioral Ecology and Sociobiology 16:337-341.

Kleiman, D. G. 1974. Patterns of behavior in hystricomorph rodents. Pages 171-209 in I. W. Rowlands and B. Weir, eds. The biology of hystricomorph rodents. Academic Press, London.

Koeppl, J. W., N. A. Slade, and R. W. Turner. 1979. Spatial associations of Rattus exulans in Central Java, Indonesia. Journal of Mammalogy 60:795-802.

Koford, R. R. 1982. Mating system of a territorial tree squirrel (Tamiasciurus douglasii) in California. Journal of Mammalogy 63:274283.

Koprowski, J. L. 1993a. Alternative reproductive tactics in male Eastern gray squirrels: "making the best of a bad job." Behavioral Ecology 4:165-171.

1993b. Behavioral tactics, copulatory success, and dominance among male fox squirrels. Ethology Ecology and Evolution 5:169-176.

Koprowski, J. L., S. R. B. King, and M. J. Merrick. 2008. Expanded home ranges in a peripheral population: space use by endangered Mt. Graham red squirrels. Endangered Species Research 4:227232.

Kraus, C., J. Künkele, and F. Trillmich. 2003. Spacing behaviour and its implications for the mating system of a small precocial mammal: an almost asocial cavy (Cavia magna)? Animal Behaviour 66:225-238.

Krivosheev, V., A. Tsvetkova, and N. Umantseva. 1983. Polymorphism by fur color and morpho physiological differences in color morphs in a tundra population of Microtus oeconomus. Zoologicheskii Zhurnal 62:1087-1096.

Kumari, S., and I. Prakash. 1981. Observations on the social behavior of the Indian desert gerbil, Meriones hurrianae. Proceedings of the Indian Academy of Sciences 90:463-471.

Kyle, C. J., T. J. Karels, C. S. Davis, S. Mebs, B. Clark, C. Strobeck, and D. S. Hik. 2007. Social structure and facultative mating systems of hoary marmots (Marmota caligata). Molecular Ecology 16:1245-1255.

Lacey, E. A., S. H. Braude, and J. R. Wieczorek. 1997a. Burrow sharing by colonial tuco-tucos (Ctenomys sociabilis). Journal of Mammalogy 78:556-562.

. 1998. Solitary burrow use by adult Patagonian tuco-tucos (Ctenomys haigi). Journal of Mammalogy 79:986-991.

Lacey, E. A., J. R. Wieczorek, and P. K. Tucker. 1997b. Male mating behaviour and patterns of sperm precedence in Arctic ground squirrels. Animal Behaviour 53:767-779.

Lacher, T. E. 1981. The comparative social behavior of Kerodon rupestris and Galea spixii and the evolution of behavior in the Caviidae. Bulletin of Carnegie Museum of Natural History 17:171.

Laconi, M. R., and A. Castro-Vazquez. 1999. Nest building and parental behaviour in two species of Calomys (Muridae, Sigmodontinae): a laboratory study. Mammalia 63:11-20.

Laconi, M. R., G. A. Jahn, and A. Castro-Vazquez. 2000. Influence of different social partners on the survival and growth of pups in two species of Calomys (Muridae Sigmodontinae). Ethology Ecologv and Evolution 12:187-196.

Lambin, X. 1997. Home range shifts by breeding female Townsend's voles (Microtus townsendii): a test of the territory bequeathal hypothesis. Behavioral Ecology and Sociobiology 40: 363-372. 
Lambin, X., and C. J. Krebs. 1991. Spatial organization and mating system of Microtus townsendii. Behavioral Ecology and Sociobiology 28:353-363.

Lambin, X., C. J. Krebs, and B. Scott. 1992. Spacing system of the tundra vole, (Microtus oeconomus) during the breeding season in Canada's western Arctic. Canadian Journal of Zoology 70:20682072.

Lane, J. E., S. Boutin, M. R. Gunn, and D. W. Coltman. 2009. Sexually selected behaviour: red squirrel males search for reproductive success. Journal of Animal Ecology 78:296-304.

Lane, J. E., S. Boutin, M. R. Gunn, J. Slate, and D. W. Coltman. 2007. Genetic relatedness of mates does not predict patterns of parentage in North American red squirrels. Animal Behaviour 74:611-619.

- 2008. Female multiple mating and paternity in free-ranging North American red squirrels. Animal Behaviour 75:1927-1937.

Leiper, B. D., and R. Robinson. 1985. Gray mutant in the Mongolian gerbil. Journal of Heredity 76:473.

Leirs, H., N. Verheyen, and R. Verhagen. 1996. Spatial patterns in Mastomys natalensis in Tanzania (Rodentia, Muridae). Mammalia 60:545-555.

Linders, M. J., S. D. West, and W. M. Vander Haegen. 2004. Seasonal variability in the use of space by western gray squirrels in southcentral Washington. Journal of Mammalogy 85:511-516.

Linn, I., and G. Key. 1996. Use of space by the African striped ground squirrel Xerus erythropus. Mammal Review 26:9-26.

Linzey, A. V. 1983. Synaptomys cooperi. Mammalian Species 210:1-5. Lock, M. L., and B. A. Wilson. 1999. The distribution of the New Holland mouse (Pseudomys novaehollandiae) with respect to vegetation near Anglesea, Victoria. Wildlife Research 26:565577.

Lozada, M., D. Torres, M. Curth, K. Heinemann, and N. Guthmann. 2001. Space use in two rodent species (Abrothrix xanthorhinus and Eligmodontia morgani) in NW Patagonia. International Journal of Ecology and Environmental Sciences 27:39-43.

Ludwig, D. R. 1981. The population biology and life history of the water vole, Microtus richardsoni. $\mathrm{PhD}$ thesis. University of Calgary.

Luis, J., A. Carmona, J. Delgado, F. A. Cervantes, and R. Cardenas. 2000. Parental behavior of the volcano mouse, Neotomodon alstoni (Rodentia: Muridae), in captivity. Цournal of Mammalogy 81:600605.

Luis, J., F. A. Cervantes, M. Martinez, R. Cardenas, J. Delgado, and A. Carmona. 2004. Male influence on maternal behavior and offspring of captive volcano mice (Neotomodon alstoni) from Mexico. Journal of Mammalogy 85:268-272.

Luque-Larena, J. J., P. López, and J. Gosálbez. 2004. Spacing behavior and morphology predict promiscuous mating strategies in the rock-dwelling snow vole, Chionomys nivalis. Canadian Journal of Zoology 82:1051-1060.

Lurz, P. W. W., J. Gurnell, and L. Magris. 2005. Sciurus vulgaris. Mammalian Species 769:1-10.

Lynch, M. F., A. L. Fresnock, and D. H. Van Vuren. 1994. Home range and social structure of the dusky-footed woodrat (Neotoma fuscipes). Northwest Naturalist 75:73-75.

Macêdo, R. H., and M. A. Mares. 1988. Neotoma albigula. Mammalian Species 310:1-7.

Madikiza, Z., S. Bertolino, and E. Do Linh San. 2011. Female in space, or female in space and time? first data on the socio-spatial organization and mating system of the woodland dormouse (Graphiurus murinus). Lournal of Ethology 29:375-380.
Madison, D. M. 1980. Space use and social structure in meadow voles, Microtus pennsylvanicus. Behavioral Ecology and Sociobiology 7:65-71.

Madison, D. M., and W. J. McShea. 1987. Seasonal changes in reproductive tolerance, spacing, and social organization in meadow voles: a microtine model. American Zoologist 27:899-908.

Magnusson, W. E., A. D. L. Francisco, and T. M. Sanaiotti. 1995. Home-range size and territoriality in Bolomys lasiurus (Rodentia: Muridae) in an Amazonian Savanna. Iournal of Tropical Ecology 11:179-188.

Maher, C. R. 2004. Intrasexual territoriality in woodchucks (Marmota monax). Journal of Mammalogy 85:1087-1094.

- 2006. Social organization in woodchucks (Marmota monax) and its relationship to growing season. Ethology 112:313-324.

Malik, A., Z. Frenkel, A. Hernandez, M. Band, E. Nevo, and A. Avivi. 2011. Characterization of paternity relationships in the mole rat Spalax ehrenbergi by microsatellite genotyping. Population Ecology 53:501-510.

Manjerovic, M. B., A. A. Kinahan, J. M. Waterman, N. C. Bennett, and P. W. Bateman. 2008. Structure and allometry of genitalia in males and females of a social African ground squirrel with high polygynandry. Journal of Zoology 275:375-380.

Marcus, M. 1984. Behavioral ecology of paca (Agouti paca) on Barro Colorado Island, Panama. MS thesis. University of Maine, Orono.

Marfori, M. A., P. G. Parker, T. G. Gregg, J. G. Vandenbergh, and N. G. Solomon. 1997. Using DNA fingerprinting to estimate relatedness within social groups of pine voles. Journal of Mammalogy 78:715-724.

Marinelli, L., and F. Messier. 1993. Space use and the social system of muskrats. Canadian Journal of Zoology 71:869-875.

Marinelli, L., F. Messier, and Y. Plante. 1997. Consequences of following a mixed reproductive strategy in muskrats. Journal of Mammalogy 78:163-172.

Marquet, P. A., L. C. Contreras, S. Silva, J. C. Torres-Mura, and F. Bozinovic. 1993. Natural history of Microcavia niata in the high Andean zone of Northern Chile. Journal of Mammalogy 74:136140.

Matocq, M. D. 2004. Reproductive success and effective population size in woodrats (Neotoma macrotis). Molecular Ecology 13:16351642.

Matocq, M. D., and E. A. Lacey. 2004. Philopatry, kin clusters, and genetic relatedness in a population of woodrats (Neotoma macrotis). Behavioral Ecology 15:647-653.

McEachern, M. B. 2005. Behavioral variation and genetic structure in dusky-footed woodrats, Neotoma fuscipes. PhD diss. University of California, Davis.

McGuire, B., and W. E. Bemis. 2007. Parental care. Pages 231-242 in J. O. Wolff and P. W. Sherman, eds. Rodent societies: an ecological and evolutionary perspective. University of Chicago Press, Chicago.

McGuire, B., E. Henyey, E. McCue, and W. E. Bemis. 2003. Parental behavior at parturition in prairie voles (Microtus ochrogaster). Lournal of Mammalogy 84:513-523.

McGuire, B., and M. Novak. 1984. A comparison of maternal behaviour in the meadow vole (Microtus pennsylvanicus), prairie vole (M. ochrogaster) and pine vole (M. pinetorum). Animal Behaviour 32:1132-1141.

1986. Parental care and its relationship to social organization in the montane vole (Microtus montanus). Journal of Mammalogy 67:305-311. 
Meier, P. T. 1992. Social organization of woodchucks Marmota monax. Behavioral Ecology and Sociobiology 31:393-400.

Meulman, E. P. 1997. The ecology of the heath mouse Pseudomys shortridgei in the Grampians National Park, Victoria. PhD thesis, Charles Sturt University, Albury.

Meulman, E. P., and N. I. Klomp. 1999. Is the home range of the heath mouse Pseudomys shortridgei an anomaly in the Pseudomys genus? Victorian Naturalist 116:196-201.

Michener, G. R. 1983. Kin identification, matriarchies, and the evolution of sociality in ground dwelling sciurids. Pages 528-572 in J. F. Eisenberg and D. G. Kleiman, eds. Advances in the study of mammalian behavior. American Society of Mammalogists.

Michener, G. R., and I. G. McLean. 1996. Reproductive behaviour and operational sex ratio in Richardson's ground squirrels. Animal Behaviour 52:743-758.

Mihok, S. 1979. Behavioural structure and demography of subarctic Clethrionomys gapperi and Peromyscus maniculatus. Canadian Journal of Zoology 57:1520-1535.

Millesi, E., S. Huber, J. P. Dittami, I. E. Hoffmann, and S. Daan. 1998. Parameters of mating effort and success in male European round squirrels, Spermophilus citellus. Ethology 104:298-313.

Mills, S. C., A. Grapputo, E. Koskela, and T. Mappes. 2007. Quantitative measure of sexual selection with respect to the operational sex ratio: a comparison of selection indices. Proceedings of the Roval Societv B 274:143-150.

Monks, N. J. 1998. Melanism in the tree squirrel, Paraxerus cepapi (A. Smith 1836) in Kyle Recreational Park, Zimbabwe. African Lournal of Ecology 36:102-103.

Moolman, M., N. C. Bennett, and A. S. Schoeman. 1998. The social structure and dominance hierarchy of the highveld mole-rat Cryptomys hottentotus pretoriae (Rodentia: Bathyergidae). Iournal of Zoology 246:193-201.

Moorhouse, T. P., and D. W. Macdonald. 2005. Temporal patterns of range use in water voles: do female's territories drift? Lournal of Mammalogy 86:655-661.

Moshkin, M. P., E. A. Novikov, and D. V. Petrovski. 2007. Skimping as an adaptive strategy in eusocial fossorial rodents: mole vole, Ellobius talpinus as an example. Pages 49-60 in S. Begall, H. Burda, and C. E. Schleich, eds. Subterranean rodents: news from underground. Springer, Berlin.

Mullican, T., and B. Keller. 1986. Ecology of the sagebrush vole (Lemmiscus curtatus) in southeastern Idaho. Canadian Journal of Zoology 64:1218-1223.

Munroe, K., and J. Koprowski. 2011. Sociality, Bateman's gradients, and the polygynandrous genetic mating system of round-tailed ground squirrels (Xerospermophilus tereticaudus). Behavioral Ecology and Sociobiology 65:1811-1824.

Murie, J. O. 1995. Mating behavior of Columbian ground squirrels. 1. Multiple mating by females and multiple paternity. Canadian Journal of Zoology 73:1819-1826.

Murphy, M. R. 1977. Intraspecific sexual preferences of female hamsters. Journal of Comparative Physiology and Psychology 91:13371346.

Myllymäki, A. 1977. Intraspecific competition and home range dynamics in the field vole Microtus agrestis. Oikos 27:553-569.

Naim, D., S. Telfer, S. Sanderson, S. Kemp, and P. Watts. 2011. Prevalence of multiple mating by female common dormice, Muscardinus avellanarius. Conservation Genetics 12:971-979.

Nakagawa, M., H. Miguchi, K. Sato, and T. Nakashizuka. 2007. A preliminary study of two pympatic Maxomys rats in Sarawak,
Malaysia: spacing patterns and population dynamics. Raffles Bulletin of Zoology 55:381-387.

Naumov, N. P., and V. S. Lobachev. 1975. Ecology of desert rodents of the U.S.S.R. (jerboas and gerbils). Pages 465-591 in I. Prakash, and P. K. Ghosh, eds. Rodents in desert environments. Junk, Hague.

Nel, J. A. J. 1975. Aspects of the social ethology of some Kalahari rodents. Zeitschrift für Tierpsvchologie 37:322-331.

Novikov, E., D. Petrovksi, I. Kolosova, S. Stenlechner, and M. Moshkin. 2004. Interactions between intruders and residents in the mole-vole Ellobius talpinus. Acta Zoologica Sinica 50:19-26.

Nutt, K. J. 2005. Philopatry of both sexes leads to the formation of multi-male, multi-female groups in Ctenodactylus gundi (Rodentia: Ctenodactylidae). Journal of Mammalogy 86:961-968.

- 2007. Genetic reconstruction of breeding patterns in gundis (Rodentia: Ctenodactylidae). Behavioral Ecology and Sociobiology 61:1651-1663.

O’Farrell, M. J., and A. R. Blaustein. 1974. Microdipodops megacephalus. Mammalian Species 46:1-3.

Ohnishi, N., T. Saitoh, and Y. Ishibashi. 2000. Spatial genetic relationships in a population of the Japanese wood mouse Apodemus argenteus. Ecological Research 15:285-292.

Oka, T. 1992. Home range and mating system of two sympatric field mouse species, Apodemus speciosus and Apodemus argenteus. Ecological Research 7:163-169.

Oliveras, D., and M. Novak. 1986. A comparison of paternal behaviour in the meadow vole, Microtus pennsylvanicus, the pine vole, Microtus pinetorum, and the prairie vole, Microtus ochrogaster. Animal Behaviour 34:519-526.

Ophir, A. G., S. M. Phelps, A. B. Sorin, and J. O. Wolff. 2007. Morphological, genetic and behavioral comparisons of two prairie vole populations in the field and laboratory. Journal of Mammalogy 88:989-999.

Ophir, A. G., A. B. Sorin, S. M. Phelps, and J. O. Wolff. 2008. Social but genetic monogamy is associated with greater breeding success in prairie voles. Animal Behaviour 75:1143-1154.

O’Shea, T. J. 1991. Xerus rutilus. Mammalian Species 370:1-5.

Ostfeld, R. S. 1986. Territoriality and mating system of California voles. Journal of Animal Ecology 55:691-706.

Ostfeld, R. S., W. Z. Lidicker Jr., and E. J. Heske. 1985. The relationship between habitat heterogeneity, space use, and demography in a population of California voles. Oikos 45:433-442.

Owen, R. D., and R. M. Shackelford. 1942. Color aberrations in Microtus and Pitymys. Journal of Mammalogy 23:306-314.

Patenaude, F. 1983. Care of the young in a family of wild beavers, Castor canadensis. Acta Zoologica Fennica 174:121-122.

Patris, B., and C. Baudoin. 2000. A comparative study of parental care between two rodent species: implications for the mating system of the mound-building mouse Mus spicilegus. Behavioural Processes 51:35-43.

Patton, J. L., and J. H. Feder. 1981. Microspatial genetic heterogeneity in pocket gophers: non-random breeding and drift. Evolution 35:912-920.

Patzenhauerová, H. 2007. The genetic structure and paternity in the natural population of the solitary mole-rat Heliophobius argenteocinereus. MS thesis. Masarykova Univerzita, Czech Republic.

Pearson, O. P. 1960. Habits of Microtus californicus revealed by automatic photographic recorders. Ecological Monographs 30:231250.

Pearson, P. G. 1953. A field study of Peromyscus populations in Gulf Hammock, Florida. Ecology 34:199-207. 
Peinke, D. M., and C. R. Brown. 2005. Burrow utilization by springhares (Pedetes capensis) in the Eastern Cape, South Africa. African Zoology 40:37-44.

Peitz, B. 1983. Recessive coat-color mutation in the spiny mouse (Acomys cahirinus). Journal of Heredity 74:59-60.

Pinter, A. J. 1979. Dominant spotting in a natural population of the vole. Iournal of Heredity 70:441-443.

Powell, R. A., and J. J. Fried. 1992. Helping by juvenile pine voles (Microtus pinetorum), growth and survival of younger siblings, and the evolution of pine vole sociality. Behavioral Ecology 3:325-333.

Prakash, I. 1975. The population ecology of the rodents of the Rajasthan desert. Pages 75-116 in I. Prakash and P. K. Ghosh, eds. Rodents in desert environments. Junk, Hague.

Prakash, I., L. R. Kametkar, and K. G. Purohit. 1968. Home range and territoriality of the northern palm squirrel, Funambulus pennanti Wroughton. Mammalia 132:604-611.

Predavec, M., and C. J. Krebs. 2000. Microhabitat utilisation, home ranges, and movement patterns of the collared lemming (Dicrostonyx groenlandicus) in the central Canadian Arctic. Canadian Journal of Zoology 78:1885-1890.

Priotto, J., A. Steinmann, and J. Polop. 2002. Factors affecting home range size and overlap in Calomys venustus (Muridae: Sigmodontinae) in Argentine agroecosystems. Mammalian Biology 67:97-104

Purohit, K. G., L. R. Kametkar, and I. Prakash. 1966. Reproduction biology and post-natal development in the northern palm squirrel Funambulus pennanti Wroughton. Mammalia 30:538-546.

Rambau, R. V., T. J. Robinson, and R. Stanyon. 2003. Molecular genetics of Rhabdomys pumilio subspecies boundaries: mtDNA phylogeography and karyotypic analysis by fluorescence in situ hybridization. Molecular Phvlogenetics and Evolution 28:564-575.

Ramey, C. A., and D. J. Nash. 1976. Coat color polymorphism of Abert's squirrel, Sciurus aberti, in Colorado. Southwestern Naturalist 21:209-217.

Randall, J. A., E. R. Hekkala, L. D. Cooper, and J. Barfield. 2002. Familiarity and flexible mating strategies of a solitary rodent, Dipodomys ingens. Animal Behaviour 64:11-21.

Randall, J. A., K. Rogovin, P. G. Parker, and J. A. Eimes. 2005. Flexible social structure of a desert rodent, Rhombomys opimus: philopatry, kinship, and ecological constraints. Behavioral Ecology 16:961973.

Randall, J. A., K. A. Rogovin, and D. M. Shier. 2000. Antipredator behavior of a social desert rodent: footdrumming and alarm calling in the great gerbil, Rhombomys opiums. Behavioral Ecology and Sociobiology 48:110-118.

Rathbun, G. B., and C. D. Rathbun. 2006. Social monogamy in the noki or dassie-rat (Petromus typicus) in Namibia. Mammalian Biology 71:203-213.

Ratkiewicz, M., and A. Borkowska. 2000. Multiple paternity in the bank vole (Clethrionomys glareolus): field and experimental data. Mammalian Biology 65:6-14.

Raun, G. G., and B. J. Wilks. 1964. Natural history of Baiomys taylori in southern Texas and competition with Sigmodon hispidus in a mixed population. Texas Journal of Science 16:28-49.

Ribble, D. O. 1991. The monogamous mating system of Peromyscus californicus as revealed by DNA fingerprinting. Behavioral Ecology and Sociobiology 29:161-166.

1992. Lifetime reproductive success and its correlates in the monogamous rodent, Peromyscus californicus. Journal of Animal Ecology 61:457-468.
2003. The evolution of social and reproductive monogamy in Peromyscus, evidence from Peromyscus californicus (the California mouse). Pages 81-92 in U. Reichard and C. Boesh, eds. Monogamy: mating strategies and partnerships in birds, humans, and other mammals. Cambridge University Press, Cambridge.

Ribble, D. O., and J. S. Millar. 1996. The mating system of northern populations of Peromyscus maniculatus as revealed by radiotelemetry and DNA fingerprinting. Ecoscience 3:423-428.

Ribble, D. O., and S. Stanley. 1998. Home ranges and social organization of syntopic Peromyscus boylii and P. truei. Journal of Mammalogy 79:932-941.

Ribble, D. O., A. E. Wurtz, E. K. McConnell, J. J. Buegge, and K. C. Welch Jr. 2002. A comparison of the home ranges of two species of Peromyscus using trapping and radioelemetry data. Lournal of Mammalogy 83:260-266.

Robitaille, J. A., and J. Bovet. 1976. Field observations on the social behaviour of the Norway rat, Rattus norvegicus. Biology of Behaviour 1:289-308.

Rodgers, A., and M. Lewis. 1996. Diet selection in Arctic lemmings (Lemmus sibiricus and Dicrostonyx groenlandicus): demography, home range, and habitat use. Canadian Journal of Zoology 64:2717-2727.

Rogovin, K. A., E. J. Heske, and G. I. Shenbrot. 1996. Patterns of spatial organization and behaviour of Pygeretmus pumilio Kerr, 1792 (Dipodidae, Rodentia): radiotelemetry study in the Dagestan desert, Russia. Journal of Arid Environments 33:355-366.

Ross, P. 1995. Phodopus campbelli. Mammalian Species 503:1-7.

Roth, V. L., and W. D. Dawson. 1996. Coat color genetics of Peromyscus. V. California blonde, a new recessive mutation in the deer mouse. Journal of Heredity 87:403-406.

Rudá, M., L. U. Kocian, N. Martínková, and D. Žiak. 2010. Population dynamics and spatial behaviour of Microtus tatricus (Arvicolinae, Rodentia). Acta Theriologica Sinica 55:81-88.

Sachser, N. 1998. Of domestic and wild guinea pigs: studies in sociophysiology, domestication and social evolution. Naturwissenschaften 85:307-317.

Sachser, N., E. Schwarz-Weig, A. Keil, and J. T. Epplen. 1999. Behavioral strategies, testis size, and reproductive success in two cavimorph rodents with different mating strategies. Behaviour 136:12031217.

Sahi, D. N., and R. Sharma. 2004. Reproductive behaviour in the northern five-striped palm squirrel Funambulus pennanti Wroughton. Uttar Pradesh Journal of Zoology 24:93-96.

Saiful, A. A., A. H. Idris, Y. N. Rashid, and N. T. F. Hayashi. 2001. Home range size of sympatric squirrel species inhabiting a lowland dipterocarp forest in Malaysia. Biotropica 33:346351.

Salvioni, M. 1988. Home range and social behavior of three species of European Pitymys (Mammalia, Rodentia). Behavioral Ecology and Sociobiology 22:203-210.

Salvioni, M., and W. Z. Lidicker. 1995. Social organization and space use in California voles: seasonal, sexual, and age-specific strategies. Oecologia 101:426-438.

Santos, J. W. A., and E. A. Lacey. 2011. Burrow sharing in the desertadapted torch-tail spiny rat, Trinomys yonenagae. Journal of Mammalogy 92:3-11.

Schmidt, N. M., T. B. Berg, and T. S. Jensen. 2002. The influence of body mass on daily movement patterns and home ranges of the collared lemming (Dicrostonyx groenlandicus). Canadian Journal of Zoology 80:64-69. 
Schradin, C., and N. Pillay. 2003. Paternal care in the social and diurnal striped mouse (Rhabdomys pumilio): laboratory and field evidence. Journal of Comparative Psychology 117:317-324.

- 2004. The striped mouse (Rhabdomys pumilio) from the succulent karoo, South Africa: a territorial group-living solitary forager with communal breeding and helpers at the nest. Lournal of Comparative Psvchology 118:37-47.

. 2005b. The influence of the father on offspring development in the striped mouse. Behavioral Ecology 16:450-455.

Schulte-Hostedde, A. I., and J. S. Millar. 2004. Intraspecific variation in testis size and sperm length in the yellow-pine chipmunk (Tamias amoenus): implications for sperm competition and reproductive success. Behavioral Ecology and Sociobiology 55:272-277.

Schulte-Hostedde, A. I., J. S. Millar, and H. L. Gibbs. 2004. Sexual selection and mating patterns in a mammal with female-biased sexual size dimorphism. Behavioral Ecology 15:351-356.

Schwagmeyer, P. L., and G. A. Parker. 1990. Male mate choice as predicted by sperm competition in thirteen-lined ground squirrels. Nature 348:62-64.

Schwagmeyer, P. L., and S. J. Woontner. 1985. Mating competition in an asocial ground squirrel, Spermophilus tridecemlineatus. Behavioral Ecology and Sociobiology 17:291-296.

Ściński, M., and Z. Borowski. 2006. Home ranges, nest sites and population dynamics of the forest dormouse Dryomys nitedula (Pallas) in an oak-hornbeam forest: live-trapping and radio-tracking study. Polish Journal of Ecology 54:391-396.

2008. Spatial organization of the fat dormouse (Glis glis) in an oak-hornbeam forest during the mating and post-mating season. Mammalian Biology 73:119-127.

Seamon, J. O., and G. H. Adler. 1999. Short-term use of space by a Neotropical forest rodent, Proechimys semispinosus. Lournal of Mammalogy 80:899-904.

Server, Z., and H. Mendelssohn. 1991. Spatial movement patterns of porcupines Hystrix indica. Mammalia 55:187-206.

Shapiro, L. E., and D. A. Dewsbury. 1986. Male dominance, female choice and male copulatory behavior in two species of voles (Microtus ochrogaster and Microtus montanus). Behavioral Ecology and Sociobiology 18:267-274.

Shargal, E., N. Kronfeld-Schor, and T. Dayan. 2000. Population biology and spatial relationships of coexisting spiny mice (Acomys) in Israel. Journal of Mammalogy 81:1046-1052.

Sharpe, F., and F. Rosell. 2003. Time budgets and sex differences in the Eurasian beaver. Animal Behaviour 66:1059-1067.

Sherman, P. W. 1989. Mate guarding as paternity insurance in Idaho ground squirrels. Nature 338:418-420.

Shibata, F., T. Kawamichi, and K. Nishibayashi. 2004. Daily restsite selection and use by the Japanese doormouse. Journal of Mammalogy 85:30-37.

Shier, D. M., and J. A. Randall. 2004. Spacing as a predictor of social organization in kangaroo rats (Dipodomys heermanni arenae). Journal of Mammalogy 85:1002-1008.

Shilova, S., and M. Kasatkin. 2000. Comparative analysis of the population structure of social vole (Microtus socialis Pall., 1773, cricetidae, rodentia) in different areas of its range. Russian Journal of Ecology 31:262-268.

Shurtliff, Q. R., D. E. Pearse, and D. S. Rogers. 2005. Parentage analysis of the canyon mouse (Peromyscus cinitus): evidence for multiple paternity. Journal of Mammalogy 86:531-540.

Sinervo, B., and K. R. Zamudio. 2001. The evolution of alternative reproductive strategies: fitness differential, heritability, and ge-

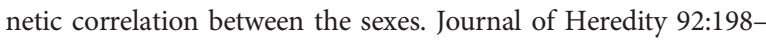
205.

Skinner, J. D., and R. H. N. Smithers. 1990. The mammals of the Southern African subregion. University of Pretoria Press, Pretoria.

Smorkatcheva, A. 2003. Parental care in the captive mandarin vole, Lasiopodomys mandarinus. Canadian Journal of Zoology 81:13391345.

Soares, M. M. 2004. Social structure in two species of communally nesting rodents. $\mathrm{PhD}$ diss. University of California, Berkeley.

Solomon, N. G., B. Keane, L. R. Knoch, and P. J. Hogan. 2004. Multiple paternity in socially monogamous prairie voles (Microtus ochrogaster). Canadian Journal of Zoology 82:1667-1671.

Sommer, S. 1997. Monogamy in Hypogeomys antimena, an endemic rodent of the deciduous dry forest in western Madagascar. Lournal of Zoology 241:301-314.

Sommer, S., D. Schwab, and J. Ganzhorn. 2002. MHC diversity of endemic Malagasy rodents in relation to geographic range and social system. Behavioral Ecology and Sociobiology 51:214-221.

Sommer, S., and H. Tichy. 1999. MHC-class II polymorphism and paternity in the monogamous Hypogeomys antimena, the endangered, largest endemic Malagasy rodent. Molecular Ecology 8:1259-1272.

Stallings, J. R., M. C. M. Kierulff, and L. F. B. M. Silva. 1994. Use of space, and activity patterns of Brazilian bamboo rats (Kannabateomys amblyonyx) in exotic habitat. Journal of Tropical Ecology 10:431-438.

Stapp, P. 1999. Size and habitat characteristics of home ranges in northern grasshopper mice (Onychomys leucogaster). Southwestern Naturalist 44:101-105.

Steele, M. A. 1999. Tamiasciurus douglasii. Mammalian Species 630:1-8.

Steinmann, A., J. Priotto, L. Sommaro, and J. Polop. 2006. Spacing behaviour of juvenile corn mice, Calomys musculinus, at the beginning of the breeding period, in absence of adult males. Acta Oecologica 29:305-310.

Steinmann, A., J. W. Priotto, E. A. Castillo, and J. J. Polop. 2005. Size and overlap of home range in Calomys musculinus (Muridae: Sigmodontinae). Acta Theriologica 50:197-206.

Stockley, P. 2003. Female multiple mating behaviour, early reproductive failure and litter size variation in mammals. Proceedings of the Roval Societv B 270:271-278.

Stoddart, D. M. 1970. Individual range, dispersion and dispersal in a population of water voles (Arvicola terrestris (L.)). Lournal of Animal Ecology 39:403-425.

Stopka, P., and R. Graciasova. 2001. Conditional allo-grooming in the herb-field mouse. Behavioral Ecology 12:584-589.

Storey, A. E., R. J. French, and R. Payne. 1995. Sperm competition and mate guarding in meadow voles (Microtus pennsylvanicus). Ethology 101:265-279.

Stuart, C., and T. Stuart. 2001. A field guide to mammals of Southern Africa. Chelsea Green, White River Junction, VT.

Suárez, O. V., and F. O. Kravetz. 2001. Male-female interaction during breeding and non-breeding seasons in Akodon azare (Rodentia, Muridae). Iheringia Serie Zoologia 91:171-176.

Sweitzer, R., and J. Berger. 1998. Evidence for female-biased dispersal in North American pocupines (Erithizon dorsatum). Iounal of Zoology 244:159-166.

Swihart, R. K., and N. A. Slade. 1989. Differences in home-range size between sexes of Microtus ochrogaster. 70:816-820. 
Taber, A. B., and D. W. MacDonald. 1992. Spatial organization and monogamy in the mara Dolichotis patagonum. Journal of Zoology 227:417-438.

Tai, F. D., and T. Z. Wang. 2000. Study on the social organization of Mandarin voles in burrow units. Acta Theriologica Sinica 20:2126.

Taitt, M. J. 1993. Adaptive coloration in Lemmus lemmus: why aren't Norwegian lemmings brown? Pages 439-446 in N. C. Stenseth and R. A. Ims, eds. The biology of lemmings. Linnean Symposium Series. Academic Press, London.

Tamura, N., F. Hayashi, and K. Miyashita. 1988. Dominance hierarchy and mating behavior of the Formosan squirrel Callosciurus erythraeus thaiwanensis. Journal of Mammalogy 69:320-331.

Tasse, J. 1986. Maternal and paternal care in the rock cavy, Kerodon rupestris, a South American hystricomorph rodent. Zoo Biology 5:27-43.

Tast, J. 1966. The root vole, Microtus oeconomus (Pallas) as an inhabitant of seasonally flooded land. Annals Zoologica Finnica 3:127171.

Taulman, J., and D. Seaman. 2000. Assessing southern flying squirrel, Glaucomys volans, habitat selection with kernel home range estimation and GIS. Canadian Field-Naturalist 114:591-600.

Taylor, M. J., and J. H. Calaby. 1988a. Rattus fuscipes. Mammalian Species 298:1-8.

- 1988b. Rattus lutreolus. Mammalian Species 299:1-7.

Thompson, K. T. 1985. Social play in the South American punaré (Thrichomys aperoides): a test of play function hypotheses. MS thesis. Virginia Polytechnic Institute and State University, Blacksburg.

Titov, S. V. 2003. Juvenile dispersal in the colonies of Spermaophilus major and S. suslicus ground squirrels. Ekologiya 4:289-295.

. 2004. Reproductive behavior of the russet souslik, Spermophilus major (Rodentia, Sciuridea). Zoologicheskii Zhurnal 83:11481159 .

Tognelli, M. F., C. M. Campos, and R. A. Ojeda. 2001. Microcavia australis. Mammalian Species 648:1-4.

Tomich, P. 1968. Coat color in wild populations of the roof rat in Hawaii. Journal of Mammalogy 49:74-82.

Tomich, P., and H. Kami. 1966. Coat color inheritance of the roof rat in Hawaii. Journal of Mammalogy 47:423-431.

Topping, M. G., and J. S. Millar. 1999. Mating success of male bushytailed woodrats: when bigger is not always better. Behavioral Ecology 10:161-168.

Travis, S. E., C. N. Slobodchikoff, and P. Kefan. 1996. Social assemblages and mating relationships in prairie dogs: a DNA fingerprint analysis. Behavioral Ecology 7:95-100.

Trillmich, F., C. Kraus, J. Künkele, M. Asher, M. Clara, G. Dekomien, J. T. Epplen, et al. 2004. Species-level differentiation of two cryptic species pairs of wild cavies, genera Cavia and Galea, with a discussion of the relationship between social systems and phylogeny in the Caviinae. Canadian Journal of Zoology 82:516-524.

Tristian, H., O. Murakami, and H. Watanabe. 2003. Ranging and nesting behavior of the ricefield rat Rattus argentiventer (Rodentia: Muridae) in West Java, Indonesia. Iournal of Mammalogy 84:1228-1236.

Turner, R., and J. Bowles. 1967. Comments on the reproduction and food habitats of the olive-backed pocket mouse in western North Dakota. Transactions of the Kansas Academv of Science 70:266267.

Ulbricha, K., and A. Kayserb. 2004. A risk analysis for the common hamster (Cricetus cricetus). Biological Conservation 117:263-270.
Urayama, K. 1995. Size and overlap of home range in a high density population of the Japanese field vole Microtus montebelli. Acta Theriologica 40:249-256.

van Hensbergen, H. J., and A. Channing. 1989. Habitat preference and use of space by the namtap Graphiurus ocularis (Rodentia: Gliridae). Mammalia 53:25-33.

Verevkin, M. V. 2006. Peculiarities of spatial organization in a midday gerbil (Meriones meridianus) population. Bulletin of Moscow Society of Naturalists 111:39-41.

Verts, B. J., and L. N. Carraway. 2003. Thomomys townsendii. Mammalian Species 719:1-6.

Vignieri, S. N. 2007. Cryptic behaviours, inverse genetic landscapes, and spatial avoidance of inbreeding in the Pacific jumping mouse. Molecular Ecology 16:853-866.

Viljoen, S. 1975. Aspects of the ecology, reproduction physiology and ethology of the bush squirrel, Paraxerus cepapi cepapi. MSc thesis. University of Pretoria.

. 1977. Behaviour of the bush squirrel, Paraxerus cepapi cepapi (A. Smith, 1836). Mammalia 41:119-165.

Waser, P. M., and J. A. De Woody. 2006. Multiple paternity in a philopatric rodent: the interaction of competition and choice. Behavioral Ecology 17:971-978.

Waterman, J. M. 1998. Mating tactics of male Cape ground squirrels, Xerus inauris: consequences of year-round breeding. Animal Behaviour 56:459-466.

Wauters, L., P. Casale, and A. A. Dhondt. 1994. Space use and dispersal of red squirrels in fragmented habitats. Oikos 69:140-146.

Wauters, L. A., J. Gurnell, D. Preatoni, and G. Tosi. 2001. Effects of spatial variation in food availability on spacing behaviour and demography of Eurasian red squirrels. Ecography 24:525-538.

Wauters, L. A., M. Zaninetti, G. Tosi, and S. Bertolino. 2004. Is coatcolour polymorphism in Eurasian red squirrels (Sciurus vulgaris L.) adaptive? Mammalia 68:37-48.

Witt, J. W. 1992. Home range and density estimates for the northern flying squirrel, Glaucomys sabrinus, in western Oregon. Iournal of Mammalogy 73:921-929.

Wlasiuk, G., J. C. Garza, and E. P. Lessa. 2003. Genetic and geographic differentiation in the Rio Negro tuco-tuco (Ctenomys rionegrensis): inferring the roles of migration and drift from multiple genetic markers. Evolution 57:913-926.

Wolff, J. O., and D. M. Cicirello. 1990. Mobility versus territoriality: alternative reproductive strategies in white-footed mice. Animal Behavoiur 39:1222-1224.

Wolff, J. O., W. D. Edge, and R. Bentley. 1994. Reproductive and behavioral biology of the gray-tailed vole. Journal of Mammalogy 75:873-879.

Wolff, J. O., and W. Z. Lidicker. 1980. Population ecology of the taiga vole, Microtus xanthognathus, in interior Alaska. Canadian Journal of Zoology 58:1800-1812.

1981. Communal winter nesting and food sharing in taiga voles. Behavioral Ecology and Sociobiology 9:237-240.

Wu, H.-Y., and H.-T. Yu. 2000. Population dynamics of the spiny country rat (Niviventer coxingi) in a subtropical montane forest in central Taiwan. Journal of Zoology 250:339-346.

- 2004. Spatial organization of a forest-dwelling murid rodent, Niviventer coxingi, in subtropical central Taiwan. Zoological Studies 43:612-621.

Wu, J.-S., P.-J. Chiang, and L.-K. Lin. 2012. Monogamous system in the Taiwan vole Microtus kikuchii inferred from microsatellite DNA and home ranges. Zoological Studies 51:204-212. 
Wynne-Edwards, K. E. 1998. Evolution of parental care in Phodopus conflict between adaptations for survival and adaptations for rapid reproduction. American Zoologist 38:238-250.

Wynne-Edwards, K. E., and R. D. Lisk. 1988. Differences in behavioral responses to a competitive mating situation in two species of dwarf hamster (Phodopus campbelli and P. sungorus). Journal of Comparative Psychology 102:49-55.

Xia, X., and J. Millar. 1991. Genetic evidence of promiscuity in Peromyscus leucopus. Behavioral Ecology and Sociobiology 28:171178.

Xie, X. M., R. Y. Sun, and J. M. Fang. 1994. The mating system and reproduction of Brandt's voles (Microtus brandti). Acta Zoologica Sinica 40:262-265.

Xu, L. 1984. The biology of Rhizomys pruinosus. Acta Theriologica Sinica 4:100-105.

Yahner, R. H. 1978. Burrow system and home range use by eastern chipmunks, Tamias striatus: ecological and behavioral considerations. Journal of Mammalogy 59:324-329.

Yeboah, S., and K. B. Dakwa. 2002. Colony and social structure of the Ghana mole-rat (Cryptomys zechi, Matchie) (Rodentia: Bathyergidae). Journal of Zoology 256:85-91.
Yin, F., and J. Fang. 1998. Mate choice in Brandt's voles (Microtus brandti). Acta Theriologica Sinica 44:162-169.

Zenuto, R. R., E. A. Lacey, and C. Busch. 1999. DNA fingerprinting reveals polygyny in the subterranean rodent Ctenomys talarum. Molecular Ecology 8:1529-1532.

Zhang, J., and W. O. Zhong. 1981. On the colonial structure of Brandt's vole in burrow units. Acta Theriologica Sinica 1:51-56.

Zhang, Y. 2007. The biology and ecology of plateau zokors (Eospalax fontanierii). Pages 237-250 in S. Begall, H. Burda, and C. E. Schleich, eds. Subterranean rodents. Springer, Berlin.

Zhong, W., G. Wang, Q. Zhou, and G. Wang. 2007. Communal food caches and social groups of Brandt's voles in the typical steppes of Inner Mongolia, China. Journal of Arid Environments 68:398-407.

Zhou, W. Y., and F. M. Dou. 1990. Studies on the activity and home range of the plateau zokor. Acta Theriologica Sinica 10:31-39.

Zwicker, K. 1989. Home range and spatial organization of the beach vole, Microtus breweri. Behavioral Ecology and Sociobiology 25:161170 .

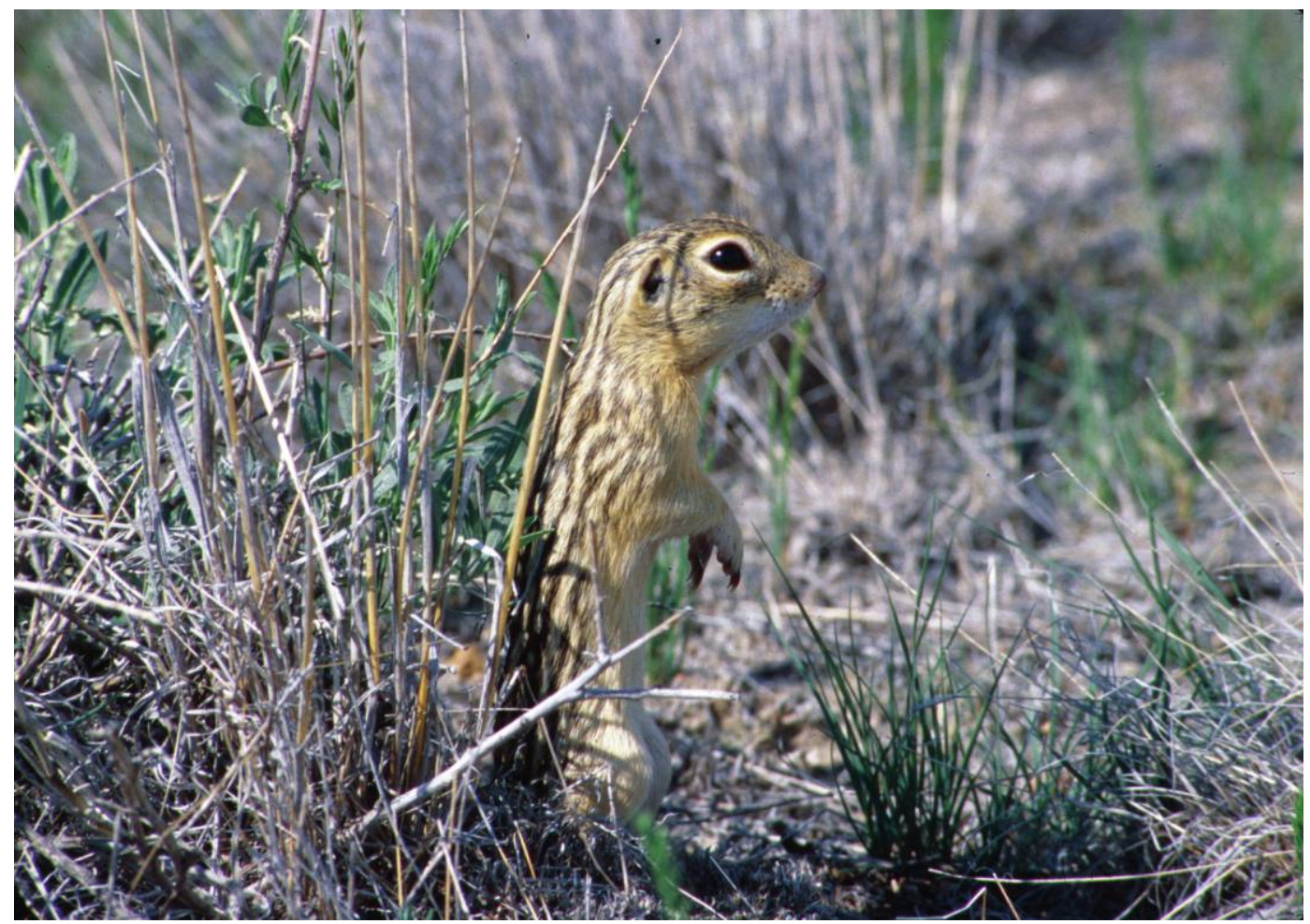

Thirteen-lined ground squirrel (Ictidomys tridecemlineatus) photographed at the Pawnee National Grassland in northeastern Colorado. Photo credit: Alexis S. Chaine. 